\title{
Determination of dissimilatory sulfate reduction rates in marine sediment via radioactive ${ }^{35} \mathrm{~S}$ tracer
}

\author{
Hans Røy ${ }^{7}$, Hannah S. Weber ${ }^{1}$, Irene H. Tarpgaard', Timothy G. Ferdelman'², and Bo B. Jørgensen \\ ${ }^{1}$ Center for Geomicrobiology, Department of Bioscience, Aarhus University, Ny Munkegade 116, 8000 Aarhus C, Denmark \\ ${ }^{2}$ Max Planck Institute for Marine Microbiology, Celsiusstr. 1, 28359 Bremen, Germany
}

\begin{abstract}
Rates of dissimilatory sulfate reduction in aquatic sediments have been measured over many years with ${ }^{35}$ radiotracer, and the method has been continuously modified and optimized. This article discusses the sequence of procedures that constitutes the method from sediment handling before incubation, via incubation and distillation, to statistical analysis of the results. We test modifications that have been added since previous method descriptions, and we recommend sound experimental procedures. We discuss the measurement of extremely low sulfate reduction rates whereby only one count per minute labeled sulfide may be produced. We show by numerical modeling that the measured rates are mostly representative for a small volume around the point where ${ }^{35} \mathrm{SO}_{4}{ }^{2-}$ is injected and that this can be used as an advantage to avoid edge effects. Finally, we show that oxidation will spoil samples during storage unless the samples are stored frozen. The main focus is on marine sediment, but the discussions are equally relevant for freshwater.
\end{abstract}

The concentration of sulfate in seawater exceeds all other dissolved electron acceptors combined by more than an order of magnitude. This allows dissimilatory sulfate reduction to persist in marine sediment long after the reactive species of more energetically favorable electron acceptors have been depleted. Thus, sulfate reduction dominates anaerobic carbon oxidation in most coastal and estuarine sediments worldwide (Goldhaber and Kaplan 1975; Jørgensen 1977, 1982; Canfield 1993). The relative importance of sulfate reduction decreases at low sedimentation rates because slowly deposited sediments are exposed to oxygen, nitrate and oxidized metals for a longer time after deposition, and because the degradability of dead organic matter decreases steeply during aging (Middelburg 1989). Sulfate reduction in deep-sea sediments therefore only contribute minutely to the global sulfur cycling

${ }^{*}$ Corresponding author: E-mail: hans.roy@biology.au.dk

\section{Acknowledgments}

This article builds on the accumulated experience collected by researchers and students at the Max Planck Institute for Marine Microbiology in Bremen and at the Center for Geomicrobiology at Aarhus University since 1992. We especially thank A. Rohwedder, K. Imhoff, J. Pedersen, and K. Henriksen for technical assistance and method tests. C. Hubert identified and shared the differential response of oxidized and reduced sediments to storage at room temperature. We thank Associate Editor Adina Paytan and two anonymous reviewers for substantial improvements to the manuscript. The study was funded by the Max Planck Society and the Danish National Research Foundation.

DOI 10.4319/lom.2014.12.196
(Canfield et al. 2005; Jørgensen and Kasten 2006) but deeply buried sediments with low metabolic activity still comprise a vast volume and the carbon mineralization in these sediments exerts major control on the climate and the chemistry of the planet.

Direct determination of sulfate reduction rates by measuring the decreasing sulfate concentration over time in a closed vial is possible in limnic sediment (e.g., Bak et al. 1991), but it is not practical in marine sediments due to the high sulfate concentration in seawater $\left(28 \mathrm{mmol} \mathrm{L} \mathrm{L}^{-1}\right)$. Typical sulfate reduction rates in coastal surface-sediments are in the order of $20 \mathrm{nmol} \mathrm{SO}{ }_{4}^{2-} \mathrm{cm}^{-3} \mathrm{~d}^{-1}$ (Jørgensen 1982). With near $20 \mu \mathrm{mol}$ $\mathrm{SO}_{4}{ }^{2-} \mathrm{cm}^{-3}$ in the sediment this implies that a $1 \%$ reduction in sulfate content requires impractically long incubation for days to months. The slow relative change in sulfate concentration is, however, turned to an advantage with radiotracer-based methods because the specific activity of the tracer remains nearly constant throughout the experiment. Because only the added tracer is measured, the high background concentration of sulfate and sulfides is of little concern. Here we re-evaluate the ${ }^{35} \mathrm{SO}_{4}{ }^{2-}$ based measurement of sulfate reduction in marine sediments that has developed into a standard method over the last 30 years.

Theoretical basis

The high activation energy of $\mathrm{SO}_{4}{ }^{2-}$ makes microbial reduction through enzymatic catalysis the only pathway of sulfate reduction within the physiological temperature range in marine sediments. Various organisms are capable of assimila- 
tory sulfate reduction to meet their anabolic demand, by far the most sulfate reduction in marine sediments is dissimilatory and coupled to respiratory oxidation of organic matter. The high activation energy of $\mathrm{SO}_{4}{ }^{2-}$ also excludes isotope exchange between sulfate-bound sulfur and reduced sulfur pools in sediments without biological catalysis. Thus, ${ }^{35} \mathrm{~S}$ added as sulfate will only be found in reduced or intermediate inorganic sulfur pools after having undergone dissimilatory reduction. The equilibrium between the various reduced sulfur species, however, are dynamic and radioactive label formed as $\mathrm{H}_{2}{ }^{35} \mathrm{~S}$ will rapidly be found also as $\mathrm{Fe}^{35} \mathrm{~S}, \mathrm{Fe}_{2}{ }^{35} \mathrm{~S}$, and ${ }^{35} \mathrm{~S}_{0}$ (Fossing and Jørgensen 1990; Fossing et al. 1992). The partly oxidized compounds can be converted back to as $\mathrm{H}_{2}{ }^{35} \mathrm{~S}$ by reduction with $\mathrm{Cr}^{2+}$, and this total pool of reducible inorganic sulfur (TRIS) must be analyzed for ${ }^{35} \mathrm{~S}$ to account for all ${ }^{35} \mathrm{SO}_{4}{ }^{2}$ that has been reduced. TRIS can be separated from sulfate (see below) and the radioactivity contained in the reduced ${ }^{35} \mathrm{~S}$ can then be determined via liquid scintillation counting with an extremely high sensitivity relative to chemical measurements and without interference from sulfides that were already present in the sediment before the incubation. Tracer experiments are further favored by the nuclear properties of ${ }^{35} S$ which make this $\beta$-emitter a near-perfect radiotracer: The decay energy of $167 \mathrm{KeV}$ is similar to that of ${ }^{14} \mathrm{C}$ and is sufficient for nearly $100 \%$ detection efficiency by liquid scintillation counting, yet low enough to be unproblematic at the low activities used in tracer experiments. The decay product ${ }^{35} \mathrm{Cl}$ is a stabile isotope that does not interfere with the experiments. The half-life of ${ }^{35} \mathrm{~S}$ is 87 days, long enough for the decay during most incubations to be insignificant, yet short enough that waste can be stored until the activity is below the limits for disposal as nonradioactive waste (subject to local regulations). The ${ }^{35} \mathrm{SO}_{4}{ }^{2-}$ tracer is relatively inexpensive and can be purchased carrierfree, dissolved in dilute hydrochloric acid.

\section{Practical application of ${ }^{35} \mathrm{SO}_{4}{ }^{2-}$}

Marine sediment can be amended with ${ }^{35} \mathrm{SO}_{4}{ }^{2-}$ by injection into intact sediment (Ivanov 1954, 1968) or by homogenously mixing sediment samples with the label diluted into anoxic sulfide-enriched seawater (Sorokin 1962). Tracer incubations work well in slurries too (e.g., Tarpgaard et al. 2011), but the method is rarely used to measure in situ rates because such manipulation of natural sediment affects SRR profoundly (Meier et al. 2000). Jørgensen and Fenchel (1974) and Jørgensen (1978) introduced the "whole-core injection" technique where distinct microliter portions of carrier-free ${ }^{35} \mathrm{SO}_{4}{ }^{2-}$ solution is injected at $\sim 1 \mathrm{~cm}$ depth intervals down through a sediment core through elastic seals in the wall of the coring tube. The intact core is then incubated at the in situ temperature for several hours. To stop incubation the core is frozen or, more often, is extruded, sectioned, and mixed with a high molarity $\mathrm{Zn}^{2+}$ solution and then frozen. The $\mathrm{Zn}^{2+}$ kills the sulfate-reducing organisms by its toxicity and by osmotic stress, and it precipitates the otherwise volatile $\mathrm{H}_{2} \mathrm{~S}$ as $\mathrm{ZnS}$. The reduced sulfur and the unreacted sulfate are separated by acidic distillation in the presence of $\mathrm{Cr}^{2+}$ (Zhabina and Volkov 1978; Howarth and Merkel 1984; Hsieh and Yang 1989; Fossing and Jørgensen 1989; Kallmeyer et al. 2004), and the radioactivity of sulfate and sulfide is determined independently. The distillation methods were initially developed to sequentially separate and quantify reduced sulfur fractions from sediments via wet chemical methods (e.g., Cline 1969), and the modern distillation techniques are still used for this purpose too. An alternative method to separate sulfide from sulfate is to place a sulfide trap within a sealed vial where acidification and reduction by $\mathrm{Cr}^{2+}$ is performed. This method relies on passive diffusion to transport $\mathrm{H}_{2} \mathrm{~S}$ from the slurry of sediment and reagents, and into the trap (Rosser and Hamilton 1983; Hsieh and Yang 1989). However, the passive distillation suffers from low recovery (Howarth and Giblin 1983), especially for elemental sulfur (Ulrich et al. 1997). Once sulfate and TRIS has been separated, by either distillation or passive diffusion, it is trivial to determine the fraction of the sulfate pool that was reduced to $\mathrm{H}_{2} \mathrm{~S}$ during incubation. If the total sulfate content in the incubated sample is also known then it is equally simple to calculate from the fraction of sulfate reduced and to the sulfate reduction rate (see details below). The concentration of sulfate can be determined from the radioactive and $\mathrm{Zn}^{+2}$ containing porewater or from a parallel sample.

Sediment from deep below the sediment-water interface retrieved by drilling or by piston or gravity coring is often subcored into plastic syringes with cut-off tip or in glass tubes fitted with syringe pistons and rubber stoppers (Fossing et al. 2000). Each of these mini-cores is injected with a single aliquot of tracer to give a coarser spatial resolution than the whole-core technique, and the individual samples are incubated for hours to days to achieve sufficient sensitivity to measure low rates of sulfate reduction. Otherwise, the samples are treated as the individual cut sections from the whole cores with multiple injections described above.

In the original description of the whole-core incubation technique, the authors specified various controls and modifications that should be considered for each new type of sediment or incubation style. Since then the method has evolved considerably, but many of the changed procedures have not been tested and verified in the peer reviewed literature. We show here that common procedures, such as storing $\mathrm{Zn}^{2+}$ fixed samples at room temperature, can lead to detrimental results. Thus, we aim to bring the method verifications up to date and to recommend good procedures for quantitative determination of dissimilatory sulfate reduction in marine sediments.

\section{Material and methods}

\section{Test sediment}

Method assessment was performed separately on reduced and on oxidized marine sediment from Aarhus Bay (Denmark). Reduced sediment was sampled with push cores from Aarhus Harbor whereas oxidized sediment was sampled at 16 
m water depth in the open Aarhus Bay $\left(56^{\circ} 09.284^{\prime} \mathrm{N} ; 10^{\circ}\right.$ $\left.19.172^{\prime} \mathrm{E}\right)$. Before use, the reduced sediment cores had the topmost $0-1 \mathrm{~cm}$ removed while for the oxidized sediment cores only the top 0-5 cm was used. Homogeneous batches of test samples were prepared by placing $\sim 500 \mathrm{~cm}^{3}$ sediment in welded oxygen-tight plastic bags and thoroughly kneading for 5 min (Hansen et al. 2000). Radioactivity corresponding to 25 $\mathrm{kBq}^{35} \mathrm{SO}_{4}{ }^{2-} \mathrm{cm}^{-3}$ sediment was injected into the plastic bags and the needle-holes sealed with vinyl adhesive tape. The bags were again kneaded thoroughly for $5 \mathrm{~min}$ and incubated at $17^{\circ} \mathrm{C}$ in darkness for 24 hours. The sediment was then mixed 1:1 with $20 \%$ Zn-acetate solution in one large batch to stop microbial activity and to fix $\mathrm{H}_{2} \mathrm{~S}$. The slurry was then transferred into individual pseudo-replicates of 1-10 g. For samples used to tests incubation termination the $\mathrm{Zn}$-acetate mix was omitted. Similar samples were prepared from the Wümme estuary in North-Western Germany for testing alternative catalytic solvents in the distillation (see below).

\section{Distillation apparatus}

The distillation setup was similar to that of Kallmeyer et al. (2004) but manufactured exclusively from glass except for seals and valves (Figs. 1 and 2). All parts were rinsed in laboratory dishwasher customized to flush all vessels and tubes with individual water jets to avoid carry-over of ${ }^{35} \mathrm{~S}$ between experiments (the loss of radioactivity from the dish washer to the sewer system is low but must be considered in relation to the permits of the lab). Low carry-over is especially critical before distillation of low-activity samples. We were not able to manually clean the glassware $(<1$ counted scintillation per minute [cpm] carryover). Radioactive sulfide was trapped either in single use plastic test tubes or directly in $20 \mathrm{~mL}$ glass scintillation vials. To avoid loss of aerosols from the widemouth scintillation vials during direct trapping the Pasteur pipette was wrapped in a small amount of cotton and inserted into the vial through a hole drilled in the lid. After distillation, the cotton was pressed into the vial and the tip of the pipette was broken off and left in the vial too. Thus, both the aerosols caught in the cotton and the sulfide that had precipitated on the Pasteur pipette was included in the scintillation counting. We used trapping in test tubes as the preferred method, but direct trapping in scintillation vials when comparing very similar samples where slight inconsistencies in the efficiency of ZnS transfer from test-tubes to the scintillation vial could not be accepted. The distillation setup consisted of 10 parallel units with individually adjustable gas flow and magnetic stirrers (Fig. 2).

\section{Reagents}

The purpose of the distillation is to convert TRIS back to $\mathrm{H}_{2} \mathrm{~S}$ that can then be flushed out of the sulfate containing solution in a $\mathrm{N}_{2}$ stream. We used $6 \mathrm{~N} \mathrm{HCl}$ to drive $\mathrm{H}_{2} \mathrm{~S}$ out of $\mathrm{ZnS}$ and $\mathrm{FeS}$. We then added $1 \mathrm{M} \mathrm{Cr}^{2+}$ in $2 \mathrm{~N} \mathrm{HCl}$ to reduce $\mathrm{FeS}_{2}, \mathrm{~S}_{0}$, and other intermediately oxidized sulfur species back to $\mathrm{H}_{2} \mathrm{~S}$. Nontoxic dimethylsulfoxide (DMSO, see below) was used as catalyst to increase the reaction rate of poorly

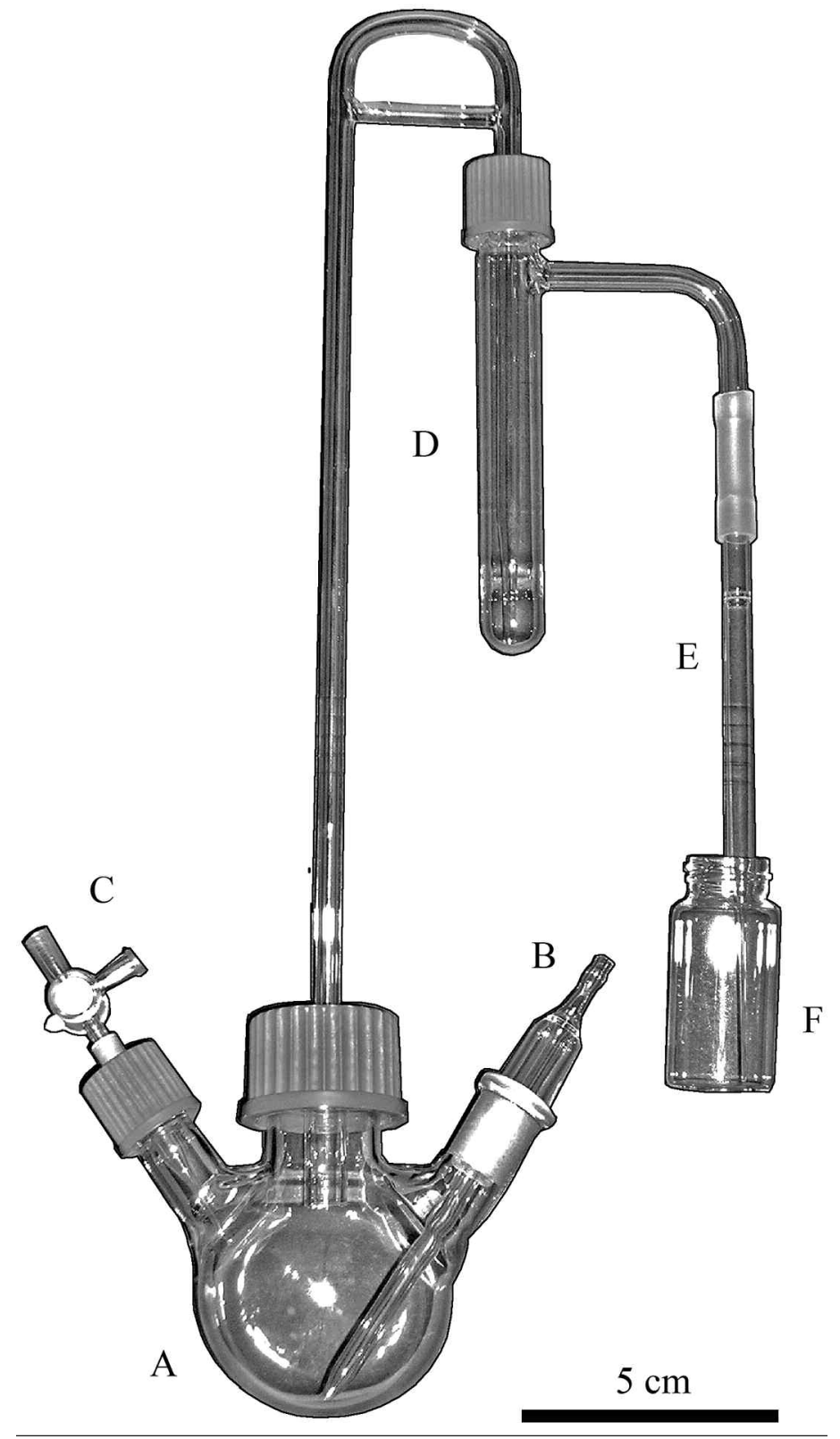

Fig. 1. Distillation glassware. A) $250 \mathrm{~mL}$ reaction flask; B) $\mathrm{N}_{2}$ inlet; C) Reagent inlet with 3-way valve; D) Aerosol trap with acidic buffer; E) Single-use Pasteur pipette; F) $\mathrm{H}_{2} \mathrm{~S}$ trap, here shown with trapping directly in a scintillation vial.

soluble species, primarily elemental sulfur. An aerosol trap containing $0.1 \mathrm{M}$ citrate buffer at $\mathrm{pH} 4$ was inserted between the reaction flak and the $\mathrm{H}_{2} \mathrm{~S}$ trap to avoid transfer of small amounts of sulfate. The final trap used to capture $\mathrm{H}_{2} \mathrm{~S}$ evolved in the reaction flask was charged with 5\% $\mathrm{Zn}$-acetate in water $(\mathrm{w} / \mathrm{w})$. We use the latest generation of high capacity scintillation cocktail (Ecoscint XR from National Diagnostics) that forms clear solutions even when mixed 2:1 with $5 \%$ Zn-acetate. See "Appendix" for a list of recommended reagents and their preparation. 


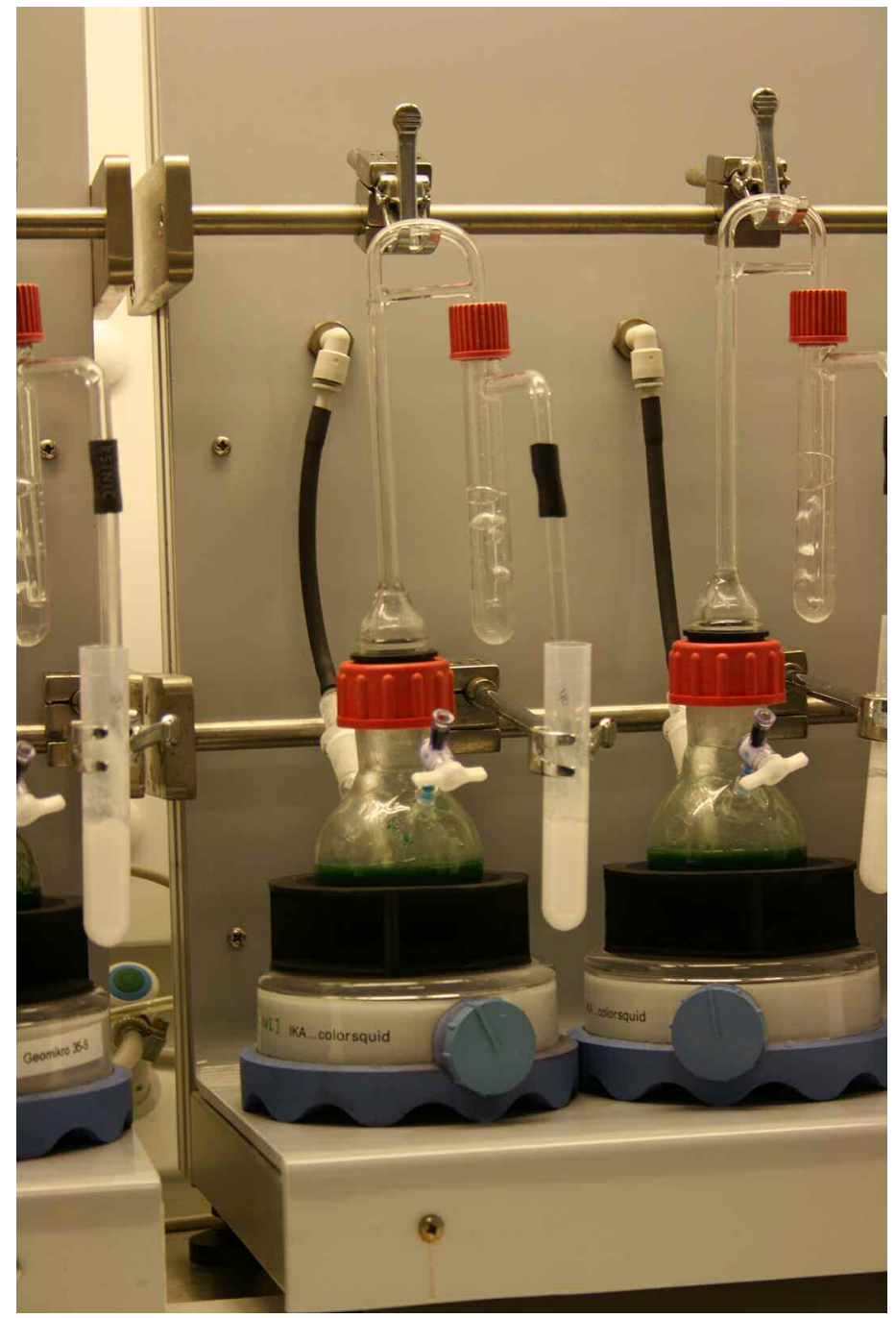

Fig. 2. Distillation apparatus with 1 out of 10 parallel reaction flasks. $\mathrm{N}_{2}$ enters from the black tube in the back and flushes the $\mathrm{H}_{2} \mathrm{~S}$ from the reaction flask via the aerosol trap and into the $\mathrm{H}_{2} \mathrm{~S}$ trap. Here shown with $\mathrm{H}_{2} \mathrm{~S}$ trapping in a single-use test tube.

\section{Distillation procedure}

All samples were fixed 1:1 with Zn-acetate before distillation. Before transfer to the reaction flask, the samples were centrifuged at $500 \mathrm{G}$ for $5 \mathrm{~min}$. A subsample for determination of ${ }^{35} \mathrm{~S}$ in sulfate was taken from the supernatant and the remaining fluid was decanted and disposed as radioactive waste. The centrifuged sediment was transferred to the reaction flask and amended with $20 \mathrm{~mL}$ DMSO, one drop of silicone-based anti-foam (Dow 362134D) and a strong almondshaped magnetic stirring bar. The reaction flasks were then closed, connected to the aerosol trap (0.1 M Citrate buffer at $\mathrm{pH} 4$ ), and the $\mathrm{H}_{2} \mathrm{~S}$ trap (5\% Zn-acetate). The $\mathrm{N}_{2}$ flow (ca. 10 $\mathrm{mL} \mathrm{min}^{-1}$ ) was started and the setup flushed for $10 \mathrm{~min}$ to expel $\mathrm{O}_{2} .8 \mathrm{~mL} 6 \mathrm{~N} \mathrm{HCl}$ was added to the reaction flask with a syringe through a valve, followed by $16 \mathrm{~mL} 1 \mathrm{M} \mathrm{Cr}^{2+}$ in $2 \mathrm{~N}$ $\mathrm{HCl}$. Sulfide was trapped in either single-use test tubes or scin- tillation vials, both containing 5-7 mL Zn-acetate solution (5\% $\mathrm{w} / \mathrm{v})$. The full content of $\mathrm{ZnS}$ suspension trapped in test tubes was transferred to a $20 \mathrm{~mL}$ scintillation vial after destination. The scintillation vials were amended with $15 \mathrm{~mL}$ scintillation cocktail and the radioactivity quantified on a Packard Tri-Carb 2900 TR liquid scintillation analyzer.

One distillation out of each 10 was dedicated to distill a killed control sample, produced by mixing a sediment sample 1:1 with $20 \%$ Zinc acetate a few minutes before adding an aliquot of ${ }^{35} \mathrm{SO}_{4}^{2-}$. The killed "blank" samples were used to verify separation efficiency and to correct for carry-over of contamination and unreacted ${ }^{35} \mathrm{SO}_{4}{ }^{2-}$ when necessary.

Sulfate analysis

Sulfate concentrations were determined by ion chromatography (Dionex ICS 2500 with AS 18 column and ED 50 suppressed conductivity detector) from parallel samples with no $\mathrm{Zn}^{2+}$ added. The samples were flushed with $\mathrm{CO}_{2}$ to remove sulfide, diluted to $>500 \mu \mathrm{mol} \mathrm{L}{ }^{-1}$, and stored at $4^{\circ} \mathrm{C}$ (not frozen) before analysis. The best performance was achieved when the salinity was diluted to below 5 PSU, but samples with very low sulfate concentration could best be analyzed undiluted. Note that the salt contents in a standard injection volume of $25 \mu \mathrm{L}$ seawater exceeds the recommended ionic load on the analytical column, but that this has no ill effects on the analysis of sulfate as long as the calibration standards are prepared with the same amount of $\mathrm{NaCl}$ as the injected samples. To separate the sulfate peak from the overwhelming chloride peak, the initial eluent concentration was kept low near $12 \mathrm{mmol} \mathrm{KOH} \mathrm{L}^{-1}$. After the sulfate peak eluted, the eluent concentration was increased to $30 \mathrm{mM}$ to strip phosphate and other strongly binding ions from the column.

It may be possible to use the aqueous phase from $\mathrm{Zn}^{2+}$ preserved incubations for analysis of porewater sulfate concentration if no parallel sample for sulfate analysis is available. Degradation of the analytical column by $\mathrm{Zn}^{2+}$ can be avoided by (1) nonsuppressed anion chromatography using low $\mathrm{pH}$ phthalate buffers (Fossing et al. 2000) or (2) chromatographic separation of $\mathrm{Zn}^{2+}$ from $\mathrm{SO}_{4}^{2-}$. We perform the latter analysis on a Metrohm 761 Compact IC (Metrohm A Supp 5 column; $3.2 \mathrm{mM} \mathrm{Na} \mathrm{CO}_{3}$ and $1 \mathrm{mM} \mathrm{NaHCO}$ eluent; $20 \mu \mathrm{L}$ sample loop) with $\mathrm{CO}_{2}$ suppression and online removal of $\mathrm{Zn}^{2+}$ (Metrohm A PPC 1 HC matrix elimination column). The 50100 fold diluted samples are injected on the PPC 1 HC matrix elimination column with water as eluent. The $\mathrm{Zn}$ cations are washed through the matrix elimination column and diverted to waste before re-eluting anions with the carbonate buffer followed by separation on the analytical column.

\section{Method assessment}

Scintillation counting in the presence of $\mathrm{Zn}$ acetate

The fraction of sulfate reduced during incubation is determined from a 0.1-1 mL sub-sample of the supernatant for determination of ${ }^{35} \mathrm{SO}_{4}{ }^{2-}$ and from the full 5-7 $\mathrm{mL}$ content of the $\mathrm{H}_{2} \mathrm{~S}$ trap for determination of ${ }^{35} \mathrm{~S}$-TRIS. The sensitivity of 
scintillation counting to varying mixing ratios between $\mathrm{Zn}$ acetate solution and scintillation cocktail was therefore tested. A fixed amount of ${ }^{35} \mathrm{SO}_{4}{ }^{2-}$ was added to $20 \mathrm{~mL}$ glass scintillation vials. Varying amounts of $5 \% \mathrm{Zn}$-acetate solution was added, and the vial filled to $20 \mathrm{~mL}$ with scintillation cocktail. All scintillation cocktails were sensitive to aqueous sample load when their specific load capacity was exceeded. Fig. 3 shows that it is imperative to use a tested high capacity cocktail and to add a similar amount of $5 \% \mathrm{Zn}$ acetate to the ${ }^{35} \mathrm{SO}_{4}{ }^{2-}$ sub-sample as is used in the $\mathrm{H}_{2} \mathrm{~S}$ trap. Likewise, the blind samples used to correct for the scintillation counters sensitivity to electronic noise, ambient $\gamma$ and cosmic radiation $(10-100 \mathrm{cpm}$ background) must be prepared with the same amounts 5\% Zn acetate and scintillation cocktail as the real samples are.

\section{Performance of DMSO catalyzed reductive distillation}

Cold distillation with addition of dimethylformamide (DMF) liberates all major fractions of TRIS $\left(\mathrm{H}_{2} \mathrm{~S}, \mathrm{FeS}, \mathrm{FeS}_{2}\right.$, and $\mathrm{S}_{0}$ ) with sufficient efficiently and with little or no transfer of $\mathrm{SO}_{4}{ }^{2-}$ (Kallmeyer et al. 2004). The toxicity of DMF, however, motivated search for alternative solvents. Distillation was tested with acetone, ethanol, iso-propanol, triethyleneglycoldimethylether, and dimethylsulfoxide (DMSO) in various concentrations. Distillation with 50\% DMSO in the reaction flask was as efficient as DMF (90\% to $110 \%$ TRIS recovery) and provided marginally better discrimination against $\mathrm{SO}_{4}{ }^{2-}$. Recovery of added elemental sulfur varied from $50 \%$ to near $100 \%$. The fraction of TRIS found as elemental sulfur is, however, low and the potential for error in calculated sulfate reduction rates caused by inefficient $\mathrm{S}_{0}$ extraction is minimal (see Gröger et al. 2009 for quntitative extraction of elemental sulfur). The only drawback using DMSO is small amounts of harmless but obnoxiously smelling DMS that are formed during distillation.

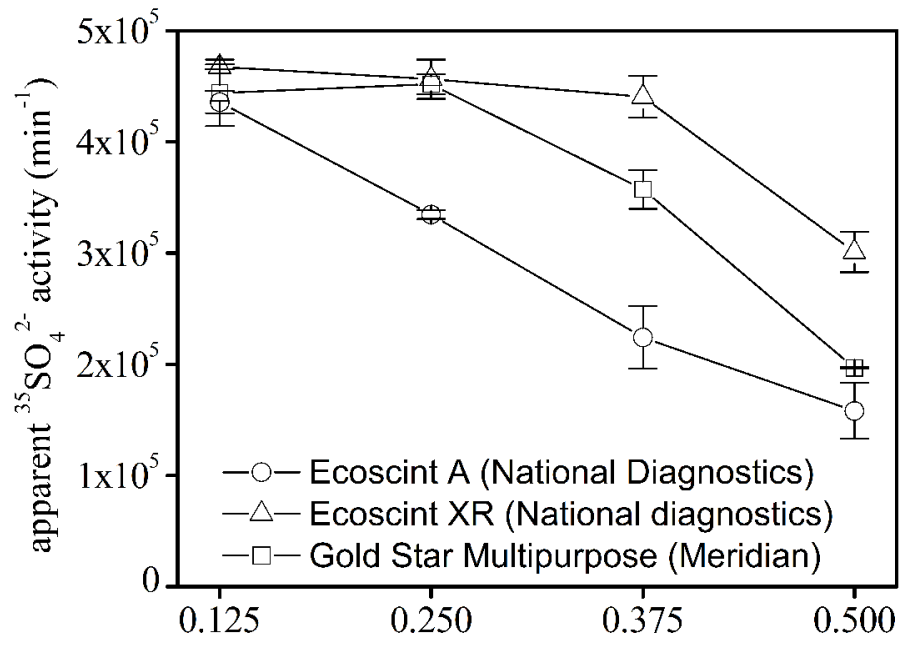

fraction of $\mathrm{Zn}$-acetate solution in counting mixture

Fig. 3. Fixed amounts of ${ }^{35} \mathrm{SO}_{4}{ }^{2-}$ measured in different mixing ratio of $5 \% \mathrm{Zn}$-acetate and scintillation cocktail. All vials were filled to $20 \mathrm{~mL}$ total volume with scintillation cocktail.
The odor problems are handled effectively by distillation in a fume hood and appropriate disposal of the waste.

The appropriate duration of distillation with DMSO in place of DMF was tested in $3 \mathrm{~g}$ pseudo-replicates prepared as described above. The samples were distilled for 3 hours in total and the $\mathrm{Zn}$-acetate traps $(5 \% \mathrm{w} / \mathrm{v}, 5 \mathrm{~mL})$ were changed every 15 min. More than $98 \%$ of the recoverable tracer was liberated within the first $30 \mathrm{~min}$ and 99.9\% within the first $60 \mathrm{~min}$ (Fig. 4). Similar distillations show that near $100 \%$ of sulfate loss in incubations can be recovered from the TRIS pool (Fig. 5).

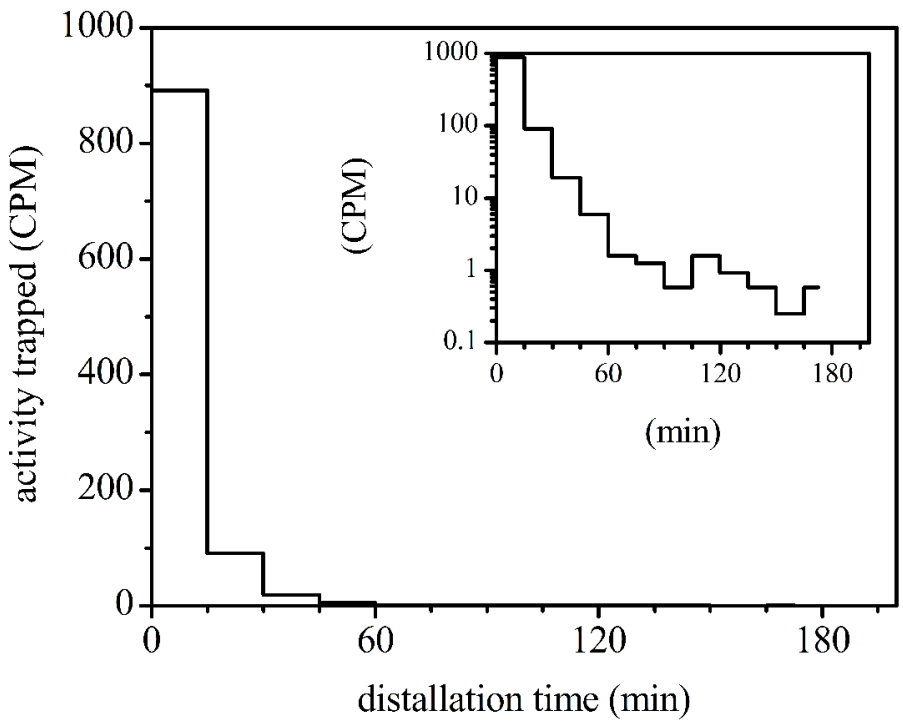

Fig. 4. Recovery of TRIS radioactivity during a 3-h distillation (average of 3 parallel distillations).

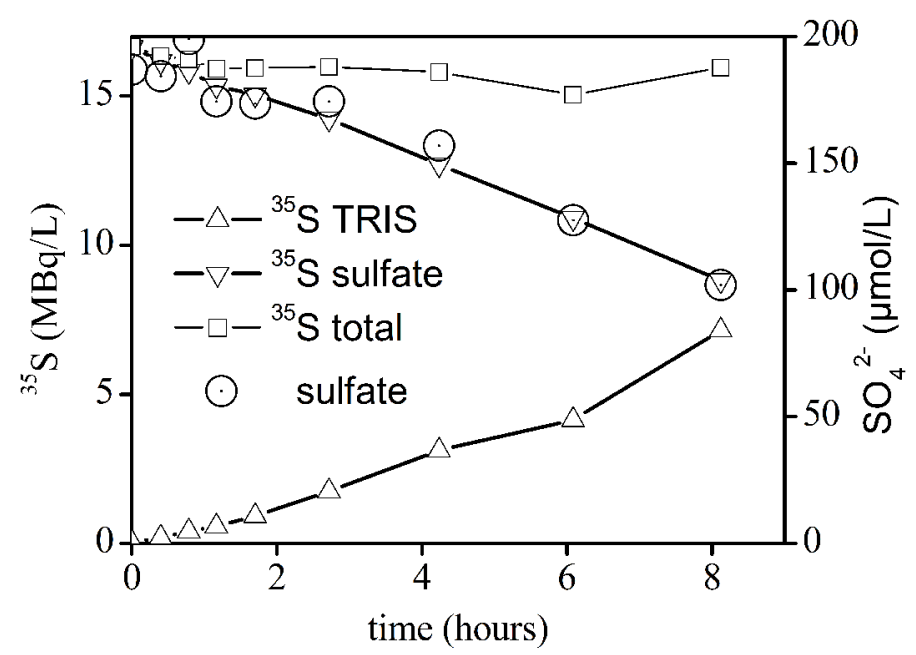

Fig. 5. Time course of sulfate depletion, ${ }^{35} \mathrm{~S}$-sulfate depletion, and ${ }^{35} \mathrm{~S}$ TRIS formation in a $D$. autotrophicum culture. Sulfate concentrations were measured by ion chromatography (IC). 


\section{Optimal sample size}

The extraction efficiency of ${ }^{35} \mathrm{~S}$-TRIS from samples of varying size was tested in the range of 0.5 to $16 \mathrm{~g}$ wet, centrifuged sediment in the reaction flask. The distillation could extract consistent amounts of TRIS radioactivity up to $16 \mathrm{~g}$ but suffered from decreased reproducibility at sample loads exceeding 3-5 g sediment. In all cases, the apparatus contained reagents in excess and drops in TRIS recovery occurred as the stirring magnets could no longer be kept properly rotating. With this distillation equipment, the sample size should preferably not exceed $5 \mathrm{~g}$ wet sediment, and close attention must be paid to proper rotation of the stirrer magnet.

Reproducibility

The volume and the specific radioactivity of the supernatant prohibit the entire supernatant sample use to determine the amount of injected ${ }^{35} \mathrm{SO}_{4}{ }^{2-}$. Instead a subsample is quantified via liquid scintillation counting and the absolute amount of ${ }^{35} \mathrm{SO}_{4}{ }^{2-}$ is calculated from the volume-specific radioactivity and the total supernatant volume. Determination of radioactivity from $100 \mu \mathrm{L}$ subsamples of supernatant initially suffered from poor precision because the $\mathrm{Zn}$ acetate containing fluid would cling to the inside of the pipette tips and introduce large volume errors. This problem was solved by amending the slurry with a measured volume of water sufficient to dilute the slurry $\sim 1: 9$ and thereby decrease the concentration of $\mathrm{Zn}$-acetate to below $2 \%(\mathrm{w} / \mathrm{w})$. Concurrently, the sampled volume for determination of ${ }^{35} \mathrm{SO}_{4}{ }^{2-}$ radioactivity was increased from 100 to $1000 \mu \mathrm{L}$. Samples with high SRR yielded a standard deviation of $\pm 5 \%$ of the calculated mean SRR when distilled simultaneously. Frozen replicates distilled by several different persons over a period of 2 months had a standard deviation of $\pm 10 \%$ (e.g., Fig. 6A).

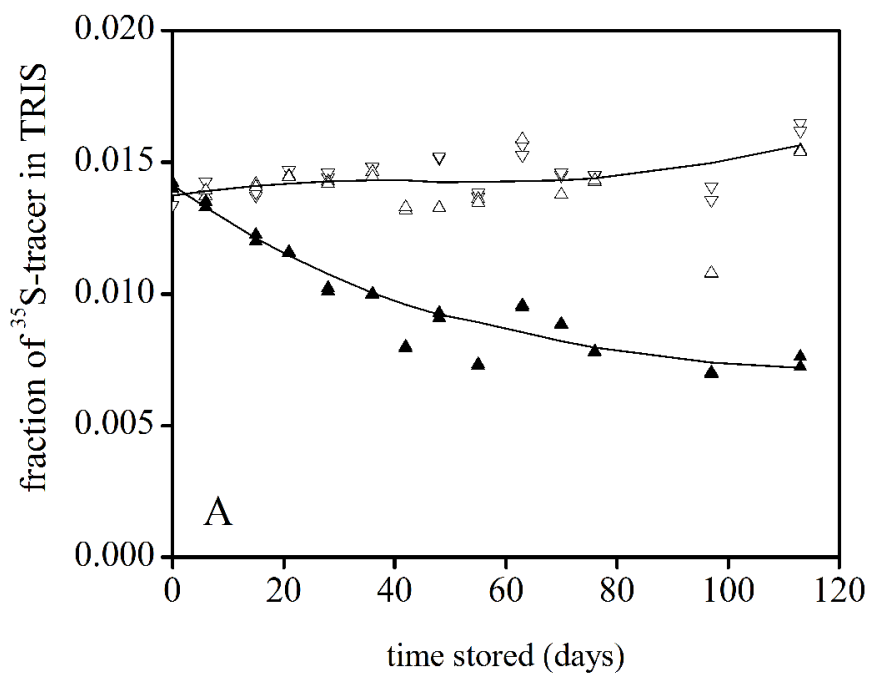

Termination efficiency

The efficiency of $\mathrm{Zn}^{2+}$ to stop sulfate reduction was tested by mixing $2 \mathrm{~cm}^{3}$ samples of homogenized sediment with $\mathrm{ZnCl}_{2}$ or $\mathrm{Zn}$-acetate solutions and immediately adding $1 \mathrm{MBq}$ ${ }^{35} \mathrm{SO}_{4}^{2-}$ radiotracer. The killed incubation was then stopped after 15 min by distillation. The production of ${ }^{35}$ S-TRIS was compared with identical samples incubated without $\mathrm{Zn}^{2+}$ addition. Killing with $20 \% \mathrm{ZnCl}_{2}$ or $\mathrm{Zn}$ acetate was instantaneous and nearly complete (Table 1 , top row). Further tests were performed by adding ${ }^{35} \mathrm{SO}_{4}^{2-}$ radiotracer after longer delays and incubating the killed sample with ${ }^{35} \mathrm{SO}_{4}{ }^{2-}$ for longer time. Even the lower concentrations of $\mathrm{ZnCl}_{2}$ eventually terminated sulfate reduction (Table 1). There was no detectable rebound in activity from potential $\mathrm{Zn}^{2+}$ tolerant sulfate reducers after 2 weeks with $5 \%$ or $20 \%$ (preservation with $1 \%$ was deemed irrelevant and not tested.). To ensure fast and effective fixation, the concentration of $\mathrm{Zn}$-fixative should be $5 \%$ or higher. Sample stability during storage

The potential loss of ${ }^{35}$ S-TRIS during storage of terminated incubations was tested in large batches of homogeneous samples prepared separately from both reduced and oxidized sediment. Incubated and homogenized sediment was transferred in aliquots of $2 \mathrm{~cm}^{3}$ to $60 \mathrm{~mL}$ centrifuge tubes and stored in one of the following three manners: 1) samples were mixed $1: 1$ with $20 \% \mathrm{Zn}$ acetate and left at room temperature, 2) samples were mixed $1: 1$ with $20 \% \mathrm{Zn}$ acetate and frozen at $-20^{\circ} \mathrm{C}$, and 3) samples were frozen at $-20^{\circ} \mathrm{C}$ with no $\mathrm{Zn}$ acetate added. The samples were distilled sequentially during the following 2 months and the fraction of the total radioactivity that was found in TRIS was quantified (Fig. 6). There was no loss of ${ }^{35} \mathrm{~S}$ TRIS for frozen samples (open symbols) regardless of the presence or absence of $\mathrm{Zn}^{+2}$. Samples stored with $\mathrm{Zn}^{2+}$ at room temperature, however, continued to lose ${ }^{35} \mathrm{~S}$-TRIS over the 2

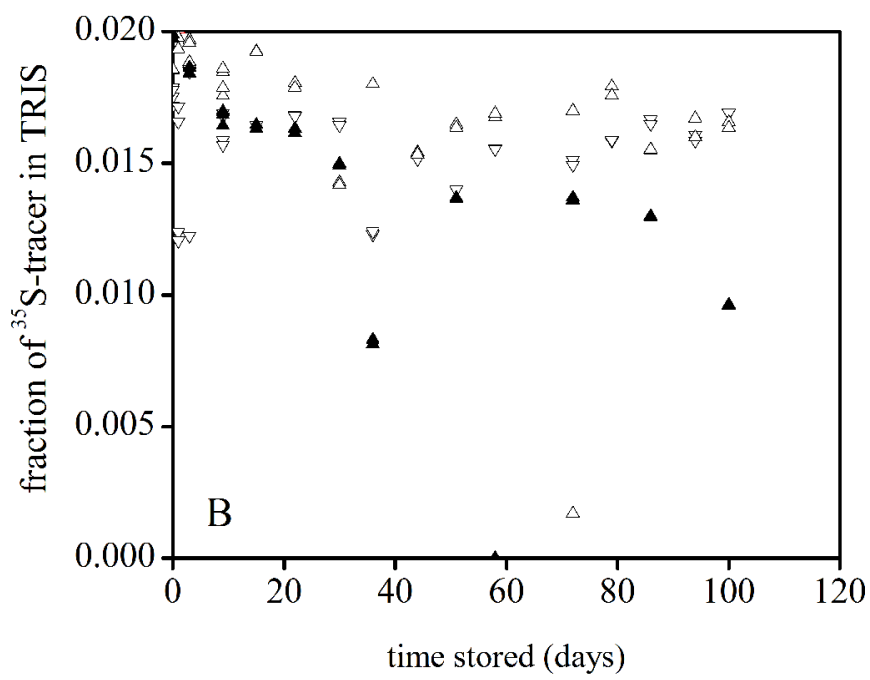

Fig. 6. Sample deterioration during storage. $\Delta$ with $\mathrm{Zn}^{2+}$ at room temperature $\left(20^{\circ} \mathrm{C}\right) ; \triangle$ with $\mathrm{Zn}^{2+}$ frozen at $-20^{\circ} \mathrm{C} ; \nabla$ without $\mathrm{Zn}{ }^{2+}$ but frozen at $-20^{\circ} \mathrm{C}$. A) Oxidized sediment, B) Reduced sediment. 
Table 1. Remaining SRR after fixation with different concentrations of $\mathrm{Zn}$ Acetate or $\mathrm{ZnCl}_{2}$. The results are given in \%o relative to unamended samples.

\begin{tabular}{|c|c|c|c|c|c|c|}
\hline & $1 \% \mathrm{ZnAC}$ & $5 \% \mathrm{ZnAC}$ & $20 \% \mathrm{ZnAC}$ & $1 \% \mathrm{ZnCl}_{2}$ & $5 \% \mathrm{ZnCl}_{2}$ & $20 \% \mathrm{ZnCl}_{2}$ \\
\hline $0-15 \min$ & 244 & 60 & 7 & 617 & 63 & $<0.4$ \\
\hline $15 \min -4 h$ & 1 & 3 & 0.5 & 29 & 5 & $<0.03$ \\
\hline $4 \mathrm{~h}-24 \mathrm{~h}$ & 5 & 0.4 & 0.06 & 4 & 0.2 & $<0.005$ \\
\hline $24 \mathrm{~h}-4 \mathrm{~d}$ & 13 & 0.04 & $<0.001$ & 0.003 & 0.003 & $<0.001$ \\
\hline $4-16 d$ & No data & n.d. & n.d. & No data & n.d. & n.d. \\
\hline
\end{tabular}

n.d. $=$ not detectable.

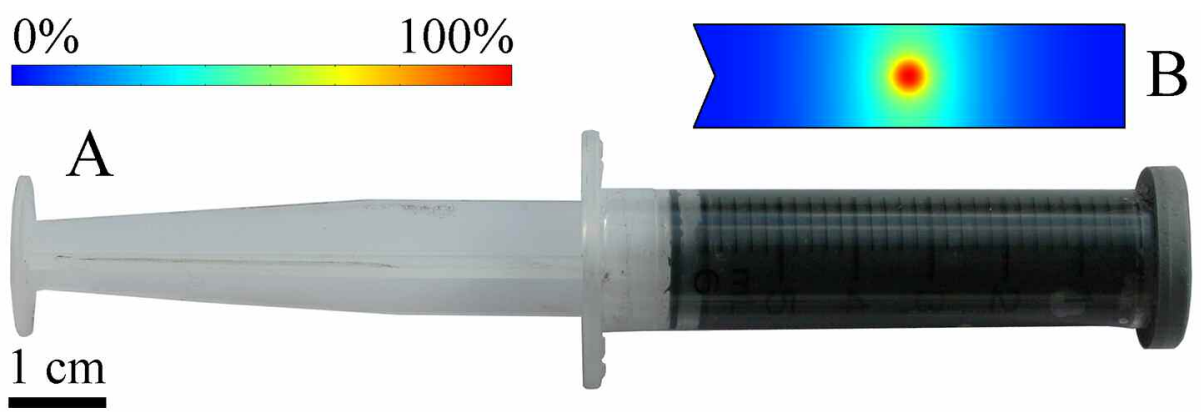

Fig. 7. Example of a sediment sample incubated in a cut-off $5 \mathrm{~mL}$ syringe (A). The syringe is closed with a Butyl stopper intended for a crimp-seal vial. B) The modeled distribution of ${ }^{35} \mathrm{~S}$-TRIS production in the cross section of the syringe after $24 \mathrm{~h}$ incubation. ${ }^{35} \mathrm{SO}_{4}{ }^{2-}$ was placed in the center of the core at time zero. The data are normalized to the highest ${ }^{35}$ S-TRIS concentration.

months of storage, most critically for the oxidized sediment. The decrease in ${ }^{35}$ S-TRIS recovery was accompanied by an increase in sulfate concentration in the slurry to far above seawater concentration. The conclusion is to always store samples frozen after incubation is terminated.

\section{Modeling of tracer distribution}

When ${ }^{35}$ S-sulfate tracer is injected into sediment, it will immediately be used by sulfate reducing bacteria, starting at the point where the tracer was injected and spreading out while ${ }^{35} \mathrm{SO}_{4}{ }^{2-}$ dissipates by molecular diffusion. The progressing spatial distribution of ${ }^{35} \mathrm{SO}_{4}{ }^{2-}$ concentration and $\mathrm{H}_{2}{ }^{35} \mathrm{~S}$ production during 24 hours of incubation was calculated in a 3dimentional finite-element model (Comsol Multiphysics). The geometry was that of a cut $5 \mathrm{~mL}$ syringe (Fig. 7A) filled with sediment (porosity 0.8) and injected in the center by $25 \mu \mathrm{L}$ of tracer solution containing $100 \mathrm{KBq}{ }^{35} \mathrm{SO}_{4}{ }^{2-}$ dissolved in water with the same sulfate concentration as the porewater $(28 \mathrm{~mol}$ $\mathrm{L}^{-1}$ ). The sulfate reduction rate in the model was $10 \mathrm{pmol} \mathrm{cm}^{-3}$ $\mathrm{d}^{-1}$. The ${ }^{35} \mathrm{SO}_{4}{ }^{2-}$ diffusion coefficient in porewater was set to $4 \times$ $10^{-10} \mathrm{~m}^{2} \mathrm{~s}^{-1}$, and all walls were assumed to be impermeable. The reduced $\mathrm{H}_{2}^{35} \mathrm{~S}$ label was not allowed to diffuse. Fig. 7B shows the distribution of immobilized $\mathrm{H}_{2}{ }^{35} \mathrm{~S}$ in the cross section of the syringe after 24 hours. Fig. 8 show distribution of ${ }^{35} \mathrm{SO}_{4}{ }^{2-}$ and the $\mathrm{H}_{2}{ }^{35} \mathrm{~S}$ along the center line of the syringe at selected times between 6 and 24 hours. Even though ${ }^{35} \mathrm{SO}_{4}{ }^{2-}$ was distributed over the entire core at the end of the incubation, most of the $\mathrm{H}_{2}^{35} \mathrm{~S}$ was still produced in a hotspot right where the tracer was

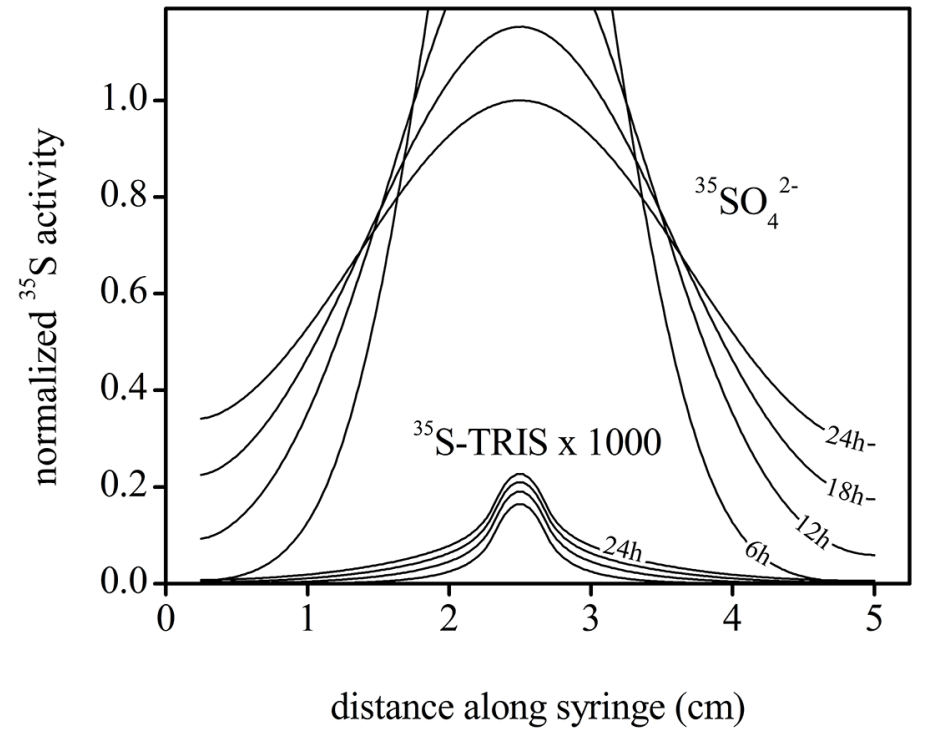

Fig. 8. Modeled distribution of ${ }^{35} \mathrm{SO}_{4}{ }^{2-}$ and immobilized ${ }^{35}$ S-TRIS along the centerline of the syringe-core after $6,12,18$, and $24 \mathrm{~h}$ of incubation. The rate of TRIS deposition in the center of the core is clearly much faster in the first $6 \mathrm{~h}$ than in the remaining $18 \mathrm{~h}$. This is caused by a high specific activity of the ${ }^{35} \mathrm{SO}_{4}{ }^{2-}$ in the center of the syringe right after injection. The concentrated spot of ${ }^{35} \mathrm{SO}_{4}{ }^{2-}$, however, disperse rapidly in all directions in the first hours of incubation. After $6 \mathrm{~h}$, the distribution is near homogeneous across the syringe and further dispersion take place only along the length of the syringe. All data are normalized to the maximum ${ }^{35} \mathrm{SO}_{4}{ }^{2-}$ concentration at time $=24 \mathrm{~h}$. 
injected. This is caused by the initially very high specific radioactivity of the added tracer here.

\section{Method verification}

As a final test of the overall ${ }^{35} \mathrm{~S}$ method, we measured and compared 1) the rate of sulfate depletion (via ion chromatography), 2) the rate of ${ }^{35} \mathrm{~S}$-sulfate depletion, and 3) the rate of ${ }^{35} \mathrm{~S}$ TRIS formation, all done simultaneously in time series using a pure culture of Desulfobacterium autotrophicum HRM2 (DSMZ 3382)L (Tarpgaard, Jørgensen, Kjeldsen and Røy; unpublished data). All measured parameters showed constant and near identical rate of sulfate reduction from time zero (Fig. 5).

\section{Discussion}

\section{General precautions}

It must first be stressed that the determination of the sulfate reduction rate in a sediment sample by incubation with ${ }^{35} \mathrm{SO}_{4}{ }^{2-}$ cannot be compared to a simple concentration measurement. It is a sensitive experiment conducted on a living community of sulfate-reducing prokaryotes. The sulfatereducing prokaryotes in sediment live on volatile fatty acids and hydrogen from fermenting organisms, and they compete for these substrates with other clades of microbes based on the presence or absence of more energetically favorable electron acceptors. Any perturbation of the microbial community or the environment, even transiently, for example from contamination by oxygen from the air, from changing temperature or pressure, or from mixing or dilution of sediment will immediately affect the sulfate reducers and their rate of metabolism. As shown above, it is possible to separate and quantify small amounts of radioactive TRIS produced in an experiment with less than 10\% error (Fig. 6). Thus, the main potential error by SRR measurements arises from failure to maintain in situ conditions. For this reason, it is important to avoid/minimize exposure to air, change in temperature or mechanical disturbance, and to use short incubation time (hours) whenever possible.

\section{Material properties of incubation tubes}

The common materials for core liners are clear polycarbonate or polymethylmethacrylate (Plexiglas). The two plastics have permeability to oxygen in the range $1.4-14 \times 10^{-6} \mathrm{nmol}$ $\mathrm{cm} \mathrm{cm}^{-2} \mathrm{~h}^{-1} \mathrm{~Pa}^{-1}$ (http://www.goodfellow.com/A/Polymethylmethacrylate.html). Thus, a $2 \mathrm{~mm}$ thick core liner with atmospheric air on the outside and anoxic sediment on the inside will leak in $0.15-1.5 \mathrm{nmol} \mathrm{O}_{2} \mathrm{~cm}^{-2} \mathrm{~h}^{-1}$ through the tube wall. Disposable syringes that are cut and used to incubate minicores have $0.95 \mathrm{~mm}$ thick polycarbonate walls and thus leak $0.3-3 \mathrm{nmol} \mathrm{O}_{2} \mathrm{~cm}^{-2} \mathrm{~h}^{-1}$. This amount of oxygen is sufficient to poison sulfate reducers in sediment with low biological activity and no buffer against oxidation in the form of FeS and $\mathrm{H}_{2} \mathrm{~S}$. Even if the samples are immediately placed in an anoxic atmosphere, the $\mathrm{O}_{2}$ dissolved in the plastic will still diffuse into the sample and potentially compromise the sample (e.g., de Brabandere et al. 2012). Oxygen leakage from the plastic can be reduced by replacing the plastic syringe with a glass tube or by pre-incubating the plastics in $\mathrm{O}_{2}$ free gas before use. All low activity samples should be protected from atmospheric oxygen during incubation, for example, by placing the small syringe-cores in an anoxic plastic bag or jar, or by incubation in large intact cores.

The injection septum used in the whole-core method was originally cast into small holes in the tube walls using onecomponent silicone glue (Jørgensen and Fenchel 1974). This technique call for precaution. First, the silicone glue contain acetic acid and the sealed core liners should therefore be allowed to bleed out acetate in water for several days before use. Otherwise, the released acetate may feed the sulfatereducing microorganisms. Second, the permeability of silicone rubber to oxygen $\left(5700 \mathrm{nmol} \mathrm{cm} \mathrm{cm} \mathrm{ch}^{-1} \mathrm{~Pa}^{-1}\right)$ is 100 times that of any other common polymer and a single septum $(3 \mathrm{~mm}$ diameter, $2 \mathrm{~mm}$ thick) will leak $43 \mathrm{pmol} \mathrm{O}_{2} \mathrm{~h}^{-1}$. A less permeable, yet highly elastic alternative is polyurethane-based elastic glue (e.g., Sikaflex 11FC). The polyurethane is less oxygenpermeable than silicone, it adheres better to plastic, and it does not contain acetate. We tested the compatibility of Sikaflex 11FC to sulfate-reducing bacteria by incubating $5 \mathrm{~mL}$ Desulfobacterium autotrophicum HRM2 (DSMZ 3382) culture ( $n$ $=8$ ) with and without $1 \mathrm{~cm}^{3}$ pieces of cured polyurethane rubber. We found no effect on the sulfate reduction rate in 2-h incubations. Similar tests should be performed with any other material used for the seals since elastic glues, particularly those for outdoor use, are often amended with biocides from the manufacturer. Regardless of the septum material, it is important to make the inner surface smooth and flush with the inner wall of the tube to reduce smearing of sediment during sampling before incubation and during extrusion for sectioning after the incubation. Note that the SRR can vary by orders of magnitude in the top $20 \mathrm{~cm}$ marine sediment and that it is, therefore, equally detrimental to smear surface-sediment deep into the core as it is detrimental to smear-labeled TRIS from the surface and down. An easy way to make perfect seals is to insert and inflate a section of a bicycle inner-tube into the predrilled tube and then mold the silicone or polyurethane against the inflated tube (use a suitable release agent on the inner-tube).

Elastic core stoppers and seals made from natural rubber should be avoided because the material absorbs $\mathrm{H}_{2} \mathrm{~S}$. Synthetic elastic materials such as Butyl rubber fare better (Elsgaard 2000), but the stopper material must be tested for $\mathrm{H}_{2} \mathrm{~S}$ adsorption in applications where the effect could influence results. Note that the seals in common syringes is a Butyl rubber that do not absorb $\mathrm{H}_{2} \mathrm{~S}$.

Tracer dosage

For good ${ }^{35} \mathrm{~S}$-TRIS counting statistics, an incubation should produce more than $3 \mathrm{~Bq}^{35} \mathrm{~S}$-activity in TRIS to allow the total count to reach 10.000 within one hour during liquid scintillation counting. A typical SRR near the sediment-water interface in coastal sediments is near $20 \mathrm{nmol} \mathrm{SO}_{4}{ }^{2-} \mathrm{cm}^{-3} \mathrm{~d}-1$, and the sulfate content is close to $20 \mu \mathrm{mol} \mathrm{cm}{ }^{-3}$. Thus, the sample will 
turn over $\sim 1 / 1000$ of the sulfate per day. To reach $3 \mathrm{~Bq}$ in TRIS during a 24-h incubation at least $3000 \mathrm{~Bq}^{35} \mathrm{SO}_{4}{ }^{2-}$ must therefore be added. Shorter incubations will need proportionally more tracer. Subsurface samples will have lower SRRs and the amount of tracer must again be increased proportionally. Note that the size of the sample does not appear in this calculation as long as the entire sample is distilled. The sensitivity of the rate measurement is not increased by larger sample size but by injecting more radiotracer and by counting all ${ }^{35} \mathrm{~S}$-TRIS formed. Note also that the amount of injected tracer does not need to be accurate because the fraction of sulfate reduced is determined by the ratio of measured total activity to measured TRIS activity. We typically use $1-100 \mathrm{KBq}$ tracer per sample, but we may increase up to $10 \mathrm{MBq}$ per experiment in deep subseafloor samples with extremely low rates of sulfate reduction.

\section{Distribution of labeled TRIS}

Fig. 7B and Fig. 8 shows where $\mathrm{H}_{2}{ }^{35} \mathrm{~S}$ forms during incubation. If $\mathrm{H}_{2} \mathrm{~S}$ diffuse freely in the sediment, it will dissipate throughout the sample via molecular diffusion just like ${ }^{35} \mathrm{SO}_{4}{ }^{2-}$. In reality, the reduced ${ }^{35} \mathrm{~S}$ label will be much less mobile than sulfate because of partial oxidation and precipitation with iron species and because of isotope exchange between $\mathrm{H}_{2} \mathrm{~S}$, FeS, $\mathrm{FeS}_{2}$, and $\mathrm{S}_{0}$. Thus, the pattern of $\mathrm{H}_{2}{ }^{35} \mathrm{~S}$ production in the figures will, in many cases, be mirrored in the distribution of ${ }^{35} \mathrm{~S}$ TRIS at the end of the incubation. Uneven distribution of ${ }^{35} \mathrm{~S}$ sulfate and ${ }^{35}$ S-TRIS does not change the calculated rate of sulfate reduction when the entire volume in a syringe is distilled or when a sample is thoroughly homogenized before a sup-sample is taken for distillation. It does, however, weigh the SRR in the center of the sediment plug much more strongly than the rates at the periphery. This is an advantage because the calculated rate of sulfate reduction will be most representative for the central part of the sample where the potential influence from contamination with atmospheric oxygen is the smallest. In whole-core incubations with multiple injections a large part of the labeled TRIS will be distributed as beads on a string independently from the final distribution of sulfate tracer. If the amount of injected tracer is variable, the distance between injection points is uneven, or the slicing is not exactly at the midpoints between injections then this will lead to point-to-point scatter in the calculated SRR. Most SRR data presented in the literature do indeed show large variability and the scatter introduced by uneven TRIS deposition is a potential, yet undetermined contributing factor.

\section{Incubation time}

It is preferable in all tracer experiments to keep the incubation time short and thereby make depletion and recycling of tracer insignificant for the rate calculation. This condition is normally met with sulfate reduction in marine surface sediments with large pools of sulfate and sulfide. Freshwater sediments can pose a problem due to the small and dynamic pool of sulfate, but the method performs well as long as the incubation time is kept short (e.g., Holmer and Storkholm 2001; King 2001). Oxidized marine sediments that support concur- rent sulfate reduction and sulfide oxidation impose a similar problem: Just like the unlabeled sulfide, radioactive ${ }^{35} \mathrm{~S}$-labeled sulfide may be oxidized back to sulfate during the incubation, which leads to apparently decreasing SRR with increasing incubation time (Jørgensen 1978; Moeslund et al. 1994). In oxidized sediments, it is therefore recommended to keep the incubation below one hour and to test the dependence of the calculated SRR on the incubation time within that time frame. In sediment obtained meters below the sediment-water interface, it is not possible to achieve sufficient sensitivity with 1$\mathrm{h}$ long incubations, and the possible effect of reoxidation must be evaluated based on the geochemistry of the core. The longest rational incubation time is set by the radioactive decay of ${ }^{35} \mathrm{~S}$ (half-life of 87 days). Long incubations will suffer from decay of radioactive TRIS and only little increase in TRIS activity is gained after more than 60 days. After 121 days, the decay of the TRIS pool will exactly balance the production of TRIS, and further incubation will lead to decreased sensitivity.

\section{Injection and incubation of whole cores}

The SRR changes radically from the sediment-water interface and a few decimeters down into the sediment in response to the prevailing electron accepting processes and the degradability of organic matter. The whole-core injection method (Jørgensen 1978) was developed to resolve this spatial distribution with minimum mechanic disturbance to the mud, minimum exposure to oxygen, and minimum disturbance of the dynamic profiles of $\mathrm{O}_{2}$ and $\mathrm{NO}_{3}^{-}$. The method works well in cohesive sediments but should be used with great caution in sand where the distribution of solutes is highly dynamic and controlled by porewater advection (de Beer et al. 2005; Jansen et al. 2009). The whole-core method can be used with millimeter-to-centimeter spatial resolution by spacing the injection septa closely and slicing the core in appropriately thin sections after incubation. Due to uneven diffusion of sulfate and TRIS (e.g., Fig. 8), we do not recommend uneven injection intervals or uneven amount of ${ }^{35} \mathrm{SO}_{4}{ }^{2-}$ per injection. Even if this leads to some waste of tracer when high spatial resolution is not required toward the bottom of the core.

\section{Injection and incubation of mini-cores}

When the required vertical resolution is coarser than one sample every few centimeters, then it is most convenient to incubate individual samples in cut-off 3-5 mL syringes (or in glass tubes). The cut syringes can be filled while cutting the liner in sections, while extruding the sediment core, or via windows cut into core-liners with a oscillating power-saw. The syringes must be filled with great care to preserve the structure of the sediment and to avoid entrapping air. Small veins of air along the syringe wall and behind the plunger can sometimes be removed by blocking the mouth of the cut syringe and compressing the sediment with the plunger while canting it. The filled syringe is sealed with paraffin-foil or a Butyl rubber stopper and immediately placed in an oxygen-reduced atmosphere until tracer injection, for example, in a continuously $\mathrm{N}_{2}$ flushed bag or jar. Note that septa for $20 \mathrm{~mm}$ crimp-seal vials 
coincidentally fit common $5 \mathrm{~mL}$ syringe barrels. Cores with low rates of metabolism and no free $\mathrm{H}_{2} \mathrm{~S}$ to act as redox buffer are best handled in a $\mathrm{H}_{2}$ free anoxic glove box. The aliquot of tracer $(2-25 \mu \mathrm{L})$ can be injected trough paraffin foil or septum and into the middle of the mini-core. This central injection causes the measurement to primarily represent the center of the core that has been the least exposed to atmospheric oxygen (Fig. 7B). The syringes may then be incubated in a welded oxygen-tight food-grade plastic bag ("Würgler-bag," Hansen et al. 2000). The bags are normally used for vacuum-sealing food, and both bags and welding machines are readily available from suppliers in the food industry. A strictly oxygen-free atmosphere during incubation can best be achieved by including a freshly opened chemical oxygen absorber that does not produce $\mathrm{H}_{2}$ (e.g., AnaeroGen, Hardy Diagnostics).

\section{Termination}

Incubation can be stopped within $10 \mathrm{~s}$ by mixing the samples 1:1 with $20 \% \mathrm{Zn}$ acetate (Table 1 ). Whole cores must be extruded and sectioned first, whereas syringe-cores can be extruded directly into centrifuge tubes preloaded with Znacetate. If timing is not critical then the incubation can be terminated by freezing. Samples incubated in cut syringes within anoxic plastic bags can be frozen without opening the bag and will freeze solid within $1 \mathrm{~h}$ at $-20^{\circ} \mathrm{C}$ and within $15 \mathrm{~min}$ at $-80^{\circ} \mathrm{C}$. Termination of whole cores by freezing is described in detail by Jørgensen (1978).

\section{Sample storage}

Samples should be distilled and the radioactivity measured soon after the experiment to avoid loss of sensitivity due to radioactive decay of ${ }^{35} \mathrm{~S}$. In time-course experiments, however, it may be most convenient to store all samples till the end of the experiment and measure all samples in one batch to avoid errors from varying counter efficiency. Radiotracer contained in sulfate or TRIS will decay proportionally during storage, and there is no need to account for this decay as long as sulfate and TRIS radioactivity is measured at the same time. During storage, the samples must remain frozen to avoid loss of ${ }^{35} \mathrm{~S}$ TRIS through oxidation (Fig. 6). Note that the addition of $\mathrm{Zn}^{2+}$ makes the samples very sensitive to autooxidation in unfrozen samples. FeS will gradually be converted to ZnS, which has the lower solubility product. The liberated $\mathrm{Fe}^{2+}$ then reacts rapidly with $\mathrm{O}_{2}$ to form a highly reactive $\mathrm{Fe}(\mathrm{III})$ species that aggressively oxidizes both $\mathrm{ZnS}$ and the $\mathrm{FeS}_{2}$ (Singer and Stumm 1970), the main components of TRIS. The result is loss of TRIS and generation of sulfate. By subsequent analysis the ${ }^{35} \mathrm{~S}$-TRIS, and thus the SRR, is underestimated. At the same time, the sulfate concentration is overestimated in case it is determined from the Zn-fixed supernatant.

\section{Distillation}

Samples that have not already been fixed with $\mathrm{Zn}^{+2}$ should be so before distillation to avoid loss of $\mathrm{H}_{2} \mathrm{~S}$ and to avoid rebound of sulfate reduction during sample handling. Frozen samples can conveniently be thawed by adding Zn-acetate solution. Before distillation, the samples are amended with a measured volume of water, sufficient to dilute Zn-acetate concentration to below $2 \%(\mathrm{v} / \mathrm{w})$ to facilitate quantitative pipetting from the supernatant as mentioned above. The samples are then centrifuged at $500 \mathrm{G}$ for $5 \mathrm{~min}$ to separate most of the ${ }^{35} \mathrm{~S}$-sulfate tracer from the sediment. The centrifugal force should not exceed 500G as firmly consolidated sediment is difficult to remove from the centrifuge tube. One milliliter of supernatant is withdrawn and mixed into $4 \mathrm{~mL}$ $5 \% \mathrm{Zn}$ acetate (to have a similar composition as the ${ }^{35} \mathrm{~S}$-TRIS sample) for later quantification of the amount of unreacted ${ }^{35} \mathrm{SO}_{4}{ }^{2-}$ in the sample. The remaining supernatant is decanted and disposed.

The reaction flasks are preloaded with one drop of siliconebased anti-foam to reduce foaming and aerosol formation (e.g., Dow 362134D). If the sample has low sulfide content then also $100 \mu \mathrm{mol}$ of a $\mathrm{ZnS}$ suspension is added as $\mathrm{H}_{2} \mathrm{~S}$ carrier to ensure quantitative transfer of $\mathrm{H}_{2}{ }^{35} \mathrm{~S}$ liberated from ${ }^{35} \mathrm{~S}$-TRIS. The sediment is transferred quantitatively to the reaction flask by washing with a small amount of water. $20 \mathrm{~mL}$ DMSO is then added, the reaction flask is closed, and the aerosol and $\mathrm{H}_{2} \mathrm{~S}$ traps and the $\mathrm{N}_{2}$ flow (ca. $10 \mathrm{~mL} \mathrm{~min}^{-1}$ ) are connected. 8 $\mathrm{mL} 6 \mathrm{~N} \mathrm{HCl}$ is slowly added to the reaction flask with a syringe through the 3-way valve to liberate $\mathrm{H}_{2} \mathrm{~S} \mathrm{ZnS}$ and FeS. Sediment with abundant sulfides and carbonates can evolve substantial

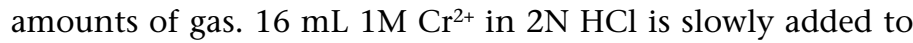
the reaction flask with a syringe trough the valve to reduce $\mathrm{FeS}_{2}$ and other intermediately oxidized sulfur species. The sample is then allowed to distill for 2 hours. After the distillation, the full content of the $\mathrm{H}_{2} \mathrm{~S}$ trap is transferred to a $20-\mathrm{mL}$ scintillation vial and $15-\mathrm{mL}$ scintillation liquid is added. Note that, at this point, the sulfate sample and the TRIS sample are in identical vials and contain identical ratios of $\mathrm{Zn}$-acetate solution and scintillation cocktail. The two samples are placed back to back in a scintillation counter that will quantify rate of radioactive decays within the vials.

\section{Calculation}

First calculate the total activity of unreacted ${ }^{35} \mathrm{SO}_{4}{ }^{2-}\left(A_{\mathrm{SO}_{4}{ }^{2-}}\right)$ from the activity of the supernatant subsample, the volume of the subsample and the total volume of fluid in the sample. Correct calculation of the fluid volume thus require knowledge of the sample volume, the water content of the sample, and the volume of $\mathrm{Zn}$ acetate and water added before centrifugation. The activity of $\mathrm{H}_{2}{ }^{35} \mathrm{~S}$ formed during incubation $\left(\mathrm{A}_{\text {TRIS }}\right)$ is simply the measured activity of the $\mathrm{H}_{2} \mathrm{~S}$ trap. The sediment-specific volumetric sulfate reduction rate (SRR) is then calculated from the following formula:

$$
S R R=\frac{F \times\left[\mathrm{SO}_{4}{ }^{2-}\right] \times 1.06 \times \phi}{t}
$$

where $\mathrm{F}$ is the fraction of ${ }^{35} \mathrm{~S}$-tracer reduced during incubation $\left(\mathrm{A}_{\mathrm{TRIS}} / \mathrm{A}_{\mathrm{SO}_{4}{ }^{2-}}+\mathrm{A}_{\mathrm{TRIS}}\right),\left[\mathrm{SO}_{4}{ }^{2-}\right]$ is the sulfate concentration in the porewater, $\varphi$ is porosity, and the incubation time. The factor 1.06 is an estimated isotope fractionation factor between ${ }^{32} \mathrm{SO}_{4}{ }^{2-}$ and ${ }^{35} \mathrm{SO}_{4}{ }^{2-}$ during bacterial sulfate reduction, 
which corrects for the slightly slower turnover of the heavy ${ }^{35} \mathrm{SO}_{4}{ }^{2-}$. The value is inferred from the ca. $40 \%$ mean fractionation in marine sediment between ${ }^{32} \mathrm{~S}$ and ${ }^{34} \mathrm{~S}$ (Canfield et al. 2010), under the assumption that the fractionation between ${ }^{32} \mathrm{~S}$ and ${ }^{35} \mathrm{~S}$ should be $50 \%$ larger.

Counting uncertainty at moderate and high rates of sulfate reduction

$\mathrm{A}_{\mathrm{TRIS}}$ and $A_{\mathrm{SO}_{4}^{2-}}$ are quantified by liquid scintillation counting and thereby associated with uncertainty according to the Poisson distribution. This error can be reduced to a small fraction of the counted value by long counting time. As a guideline, the $95 \%$ confidence interval around a counted number is $49 \%$ at 100 counts, $12 \%$ at 1000 counts, and $4 \%$ at 10.000 counts. Thus, precision of the quantification can be chosen almost freely as long as the activity is high enough to count 10.000 disintegrations within an acceptable time. The ultimate precision of a single radiotracer assay is therefore controlled by the ability to separate the small fraction of label in TRIS from a vast amount of non-reacted ${ }^{35} \mathrm{SO}_{4}{ }^{2-}$ in a consistent manner (see Kallmeyer et al. [2004] for strategies for high performance separation) and by the precision of the sulfate concentration measurement. The separation performance can be determined by distilling "blanks" in the form of Zn-acetate killed sediment samples amended with tracer after Zn-fixation. Careful handling and thorough cleaning of the distillation apparatus can assure that there is no carryover of labeled TRIS from previous distillations. The blank can thus be reduced to about one CPM above the counter background (1520 CPM in most precision instruments). We are not aware of published blank-quantification during passive (diffusive) $\mathrm{H}_{2} \mathrm{~S}$ trapping, but we have not been able to match the performance of the distillation using passive methods.

The raw data for calculation of ${ }^{35} \mathrm{SO}_{4}{ }^{2-}$ activity must be corrected for the counter background. This is uncritical because the subsample of the supernatant used to quantify ${ }^{35} \mathrm{SO}_{4}{ }^{2-}$ activity will produce $10^{3}-10^{5} \mathrm{CPM}$. The raw data for determination of ${ }^{35} \mathrm{~S}$-TRIS must, in addition, be corrected for radioactivity contributed by carryover of unreacted ${ }^{35} \mathrm{SO}_{4}{ }^{2-}$ and by contamination from previous distillations (the blank). It is straightforward to quantify the average contribution of the blank to the total counted number during measurement of ${ }^{35}$ S-TRIS, but it is not possible to determine the blank associated any real sample. The confidence in the blank-corrected TRIS radioactivity will therefore depend on the predictability of the blank. A pragmatic approach, which works well when the counted number is much larger than the blank, is to calculate $A_{\text {TRIS }}$ by subtracting the median of the blanks from the total count and to ignore the uncertainty from the counting statistics. As a guideline, this can be done when the total TRIS activity is 10 times larger than the average blank and the variance of the blank is of the same order of magnitude as the mean. If sulfate reduction rates are calculated this way then the lowest number of counted scintillations $(\mathrm{CPM} \times$ counting time) should be reported together with the mean and variance of multiple blanks.

\section{Error estimation near the detection limit}

At extremely low rates of sulfate reduction, the trapped TRIS radioactivity will ultimately approach that of "blank" samples, which have been killed with Zn-acetate before addition of tracer. It is, however, still possible to quantify the sulfate reduction rate even when the added counts from TRIS are just a small fraction of the background. To illustrate this, we consider a distillation run where the average of many blank samples was 19 counts per minute and an actual TRIS sample produced 21 counts per minute. Note that these numbers include the counter background that comes from electrical noise, ambient $\gamma$, and cosmic radiation. Note also that the sample is just barely above the blank and that a more typical sample with high SRR would produce in excess of 100 counts per minute. The sample has been counted for $20 \mathrm{~min}$, and the total count from the TRIS trap is therefore 420 while the expected contribution from the blank is 380. Although we know the average contribution of the blank we cannot simply subtract that from the trap count to calculate the contribution of TRIS from the experiment $\left(\mathrm{A}_{\mathrm{TRIS}}\right)$ because the true blank is subject to stochastic variability and therefore uncertain. For correct error estimation in an individual rate determination, we must therefore consider the probability density distribution of the blank. If the distillation is performed carefully then the counted blank values will be low and the distribution of the counted numbers will be dominated by Poisson noise according to the law of small numbers (Bortkiewicz 1898). This condition can be identified by the variance of multiple blanks as the variance is identical to the mean in the Poisson distribution. In our case, we can use the Poisson distribution with a mean value of 380 as the distribution of the unknown blank (Fig. 9A).

The probability density distribution of $A_{\text {TRIS }}$ is the total count of the sample minus the probability density distribution of the blank (Fig. 9B). However, this distribution of "possible" blanks extends beyond the total radioactivity of the sample and that causes a part of the "possible" $\mathrm{A}_{\text {TRIS }}$ values in Fig. 9B to be negative. This region must be cropped and the distribution renormalized to reflect that the unknown blank cannot possibly have been larger than the counted number. Fig. 9C shows all the possible count numbers that $A_{\text {TRIS }}$ could have contributed and their associated probabilities. It is derived by cropping the negative numbers from $7 \mathrm{~B}$ and renormalizing the area below the curve to 1. Each counted number in Fig. 9C represents a random sample and could therefore each represent a wide range of true average activities. For each possible $\mathrm{A}_{\text {TRIS }}$ in the probability density distribution we must therefore consider a range of possible true values. This is reflected by calculating the inverse Poisson distribution for each value in Fig. 9C and multiplying the distribution with probability associated to the value (Fig. 9D, lower curves). All Poisson curves are then summed to give a probability density distribution of the true $A_{\text {TRIS }}$ (Fig. 9D, upper curve). The most probable amount of radioactivity stemming from sulfate reduction and the bonds 

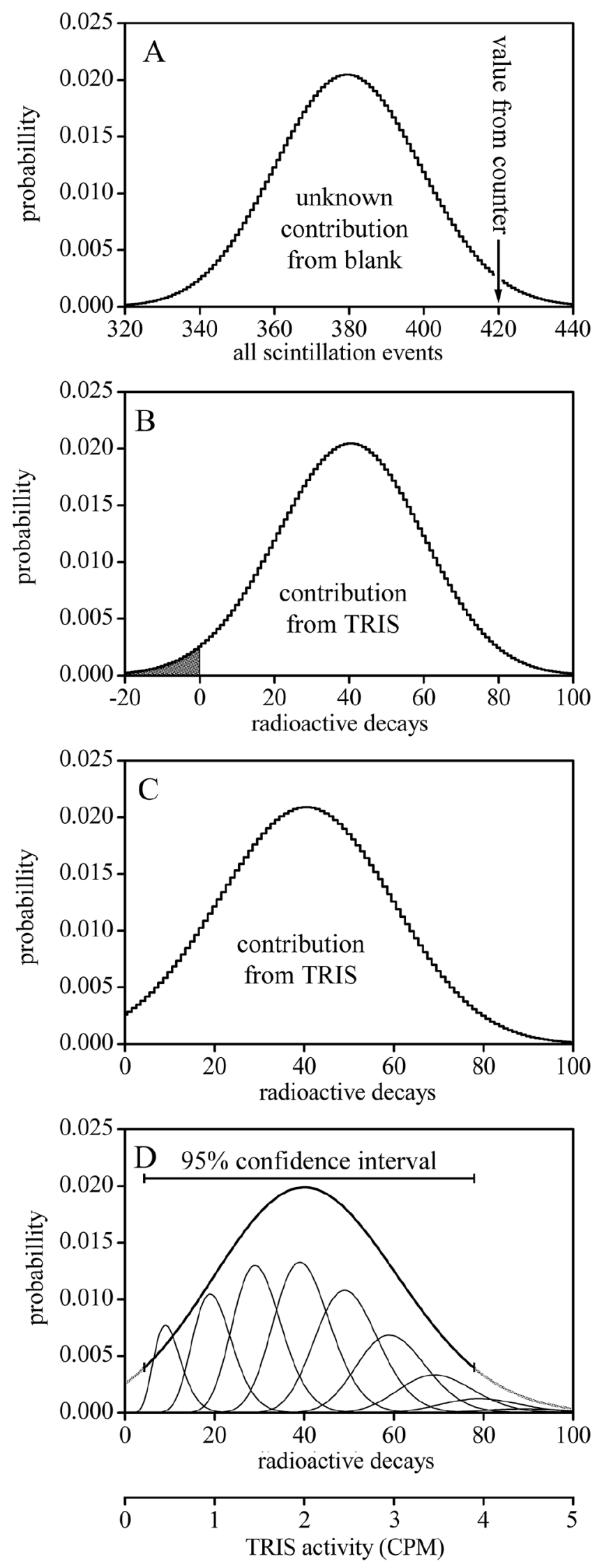

of the $95 \%$ confidence interval can then be found empirically from the distribution. The procedure is discussed by Teubner and Bruchle (2003).

\section{Examples of procedures}

There is no single set of recommended procedures for determination of sulfate reduction rates because procedures must be adapted to the style of sampling and to the expected SRR. The following sets of procedures are representative examples. The procedures can be modified based on the discussions above.

\section{Example of procedures for incubation in cut syringes \\ Sediment sampling}

Collect a long sediment core by, for example, a gravity corer. Pull the core liner from the corer and cap the ends (Fig. 10A). Store the core at in situ temperature for no more than 24 hours before subsampling. Use an oscillating power saw (e.g., Bosh MX25E or Fein Multimaster) to cut $5 \times 10 \mathrm{~cm}$ windows into the liner every $10-30 \mathrm{~cm}$ along the length of the core (Fig. 10B). Scrape the outer $5 \mathrm{~mm}$ of sediment away from the surface to avoid the smeared sediment that is contaminated by seawater. Fill a cut-off $5 \mathrm{~mL}$ syringe with sediment through each cut window (Fig. 10C). The syringes must be filled with great care to preserve the structure of the sediment and to avoid entrapment of air. Seal the mouth of each syringe with a butyl stopper intended for a $20 \mathrm{~mm}$ crimp-seal vial. Replace the filled syringe in its packing sleeve. Take a parallel sample for determination of porosity next to each sample for SRR. Take a parallel sample for determination of sulfate concentration in the porewater next to each sample for SRR (Fig.

Fig. 9. Steps in the calculation of the probability density distribution of the true TRIS value from a distillation where the TRIS sample produced 21 counts per minute and the average distillation blank (including counter background) was 19 counts per minute. The sample was counted for 20 min so the actual counted number for the TRIS sample was 420 and the expected blank was 380. A) The counted number 420 and the probability density distribution that shows what the blank value could have been based on the Poisson distribution with a mean value of 380. B) All possible blank values have been subtracted from the counted value. This represents all decay counts that could have come from TRIS radioactivity, and the probability of each of them to be true. Note that some "possible" counted numbers are negative and that is clearly nonsense. C) The negative range of possible TRIS values has been deleted and the area under the curve renormalized to 1 . This distribution represents all possible counted values that could have been contributed by radioactive TRIS and their associated probabilities. D) Each point in C could represent any underlying Poisson distribution. Thus, we calculate the inverse Poisson distribution for each point in C (every tenth curve is indicated in D and the curves are multiplied by 10 for clarity) and add up all the curves to derive the upper curve in D. This represents all possible true amounts of radioactivity in the sample contributed from sulfate reduction and their associated probability. To derive the $95 \%$ confidence interval, we delete values with low probability until $95 \%$ is left. Note that the distribution is asymmetric, and that we, in this case, remove more from the right side of the curve than from the left side. The maximum likelihood estimation is the median of the distribution (40). As the sample was counted for $20 \mathrm{~min}$, this corresponds to 2 CPM from TRIS. Note that this value is significantly different from zero, although the background was 19 CPM and thereby almost ten times larger than the signal. 


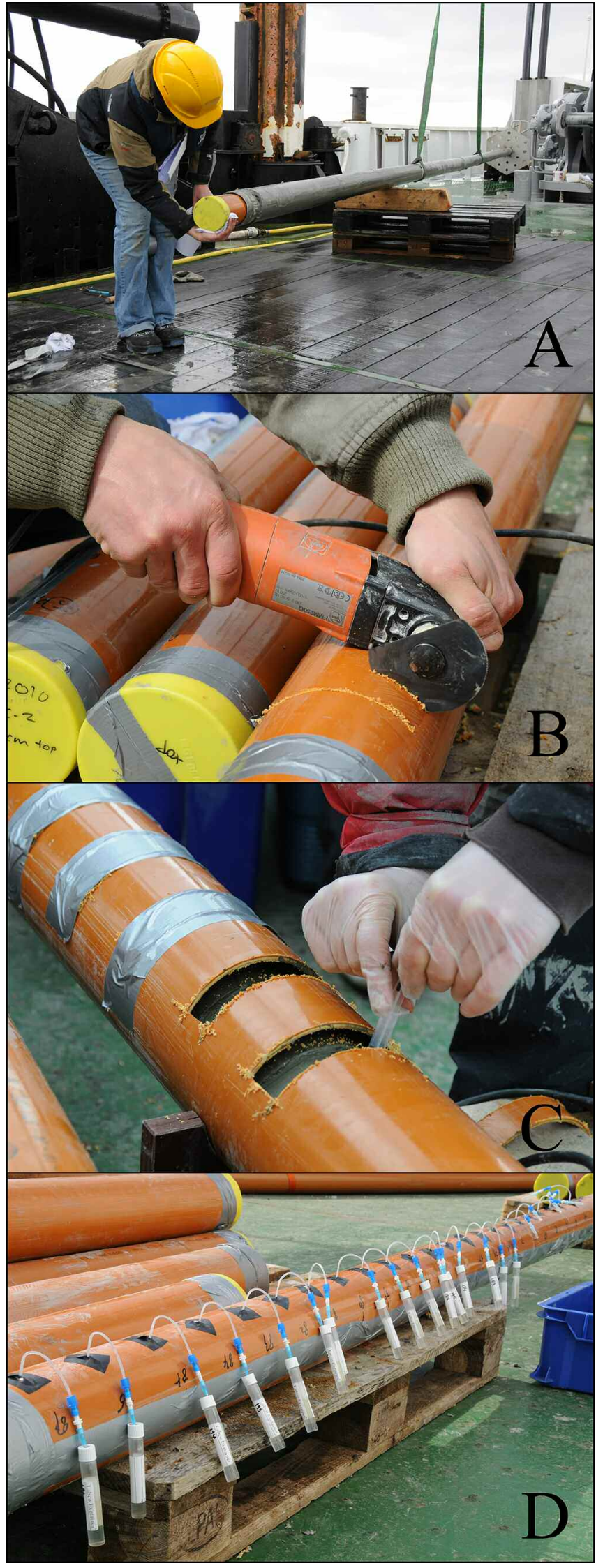

10D). Collect the filled syringes in a $20 \times 40 \mathrm{~cm}$ large $\mathrm{O}_{2}$ tight bag. Flush the bag with $\mathrm{N}_{2}$ and close it temporarily by folding and clamping. Store the samples dark at in situ temperature until tracer injection.

\section{Tracer injection and incubation}

Inject $10 \mu \mathrm{L}$ tracer solution containing $100 \mathrm{KBq}^{35} \mathrm{SO}_{4}{ }^{2-}$ dissolved in sterile tap water through the stopper and into the center of each sample. Re-insert the syringe in the sleeve to contain radioactive contamination and replace the syringe back in the plastic bag. Place an opened oxygen scrubber (e.g., AnaeroGen, Hardy Diagnostics) in the bag when all the syringes are filled. Expel as much air as possible and seal the bag with an air-tight welding. Place the bag flat on a surface with no contact between the AnaeroGen and the samples. Place a plastic bag filled with water at in situ temperature on top of the AnaeroGen to absorb the heat generated by its reaction with the remaining oxygen in the bag. Incubate at in situ temperature for 24 hours. Stop the incubation by moving the unopened bag to a $-80^{\circ} \mathrm{C}$ freezer. The bag can be transferred to $-20^{\circ} \mathrm{C}$ once the samples are frozen solid.

\section{Destillation}

Extrude the frozen samples into $50 \mathrm{~mL}$ centrifuge tubes and add $5 \mathrm{~mL}$ of $20 \% \mathrm{Zn}$ acetate to kill and thaw. Add $30 \mathrm{~mL}$ water to facilitate quantitative pipetting and centrifuge at 500G for 5 min to roughly separate the sulfate that is soluble from the TRIS that is all insoluble after fixation with $\mathrm{Zn}^{2+}$. Transfer 0.5 $\mathrm{mL}$ of the supernatant together with $4.5 \mathrm{~mL} 20 \% \mathrm{Zn}$ acetate and $15 \mathrm{~mL}$ scintillation cocktail to a $20 \mathrm{~mL}$ scintillation vial for determination of ${ }^{35} \mathrm{~S}$ in sulfate. Decant and dispose the remaining fluid as radioactive waste. Transfer each sediment sample to a reaction flask (Fig. 1) by flushing with a small amount of water. Add $20 \mathrm{~mL}$ DMSO, one drop of siliconebased anti-foam (Dow 362134D), and a strong almond-shaped magnetic stirring bar. Close the reaction flasks and connect the aerosol trap $(0.1 \mathrm{M}$ Citrate buffer at $\mathrm{pH} 4)$ and the $\mathrm{H}_{2} \mathrm{~S}$ trap (5 mL 5\% Zn-acetate plus one drop of anti-foam). Start the $\mathrm{N}_{2}$ flow (ca. $10 \mathrm{~mL} \mathrm{~min}^{-1}$ ) and flush for $10 \mathrm{~min}$ to expel most $\mathrm{O}_{2}$ from the reaction flask. Add $8 \mathrm{~mL} 6 \mathrm{~N} \mathrm{HCl}$ followed by $16 \mathrm{~mL}$ $1 \mathrm{M} \mathrm{Cr}^{2+}$ in $2 \mathrm{~N} \mathrm{HCl}$ with syringes through the valve and distill for $2 \mathrm{~h}$ (Fig. 2). During the distillation, the TRIS will be converted to $\mathrm{H}_{2} \mathrm{~S}$ and carried to the $\mathrm{H}_{2} \mathrm{~S}$ trap where it is precipitated as a white $\mathrm{ZnS}$ dispersion. Sulfate will remain in the reaction flask and can be disposed as obnoxious (DMS) smelling radioactive waste. Transfer the full content of the $\mathrm{H}_{2} \mathrm{~S}$ trap to

Fig. 10. Sampling of sediment for determination of sulfate reduction rates by a $6 \mathrm{~m}$ gravity corer. A) The core has just been received on deck, the core catcher has been removed, and the core liner inside the steel tube has been capped and labeled. B) Cutting windows into the core liner with an oscillating saw. C) Filling of a cut syringe with sediment. The core was sulfidic and contained enough buffer capacity against oxygen to allow fast sampling without a glove box. D) Rhizons inserted into the core liner for extraction of pore water for sulfate analysis. The glass vials are flushed with $\mathrm{N}_{2}$ and evacuated and provide the suction necessary to extract pore water. 
a $20 \mathrm{~mL}$ scintillation vial together with $15 \mathrm{~mL}$ scintillation fluid. Place the scintillation vials containing the supernatant subsample and the TRIS sample back to back in the scintillation counter and quantify the activity of ${ }^{35} \mathrm{~S}$ in each.

\section{Calculations}

Calculate the total amount of water in each sample from the sediment volume, the sediment porosity, the added Znacetate, and the water added before centrifugation. Calculate the total amount of ${ }^{35} \mathrm{SO}_{4}{ }^{2-}$ at the end of the incubation $\left(\mathrm{A}_{\mathrm{SO}_{4}{ }^{2-}}\right)$ from the radioactivity of the supernatant subsample and the total amount of water. Calculate the fraction of sulfate that

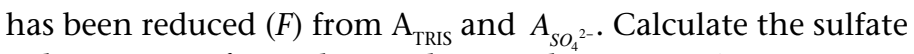
reduction rate for each sample according to Eq. 1.

\section{Example of procedures for incubation in whole cores}

\section{Sediment sampling}

Prepare a core liner for whole-core incubation by drilling a line of $3 \mathrm{~mm}$ holes $10 \mathrm{~mm}$ apart along the entire length of a 25 $\mathrm{cm}$ long polycarbonate tube with an inner diameter of $2.8 \mathrm{~cm}$. The core should be small diameter to avoid excessive amounts of labeled sediment that cannot be distilled. Plug the holes with Sikaflex 11FC and allow the glue to cure. Rinse the core thoroughly to remove water soluble contaminants from the cured glue. Collect a vertical sediment core in the perforated tube and close the lower end with a rubber stopper. Allow 2-5 $\mathrm{mm}$ water on top of the sediment and keep the top of the core open to avoid anoxic conditions at the sediment-water interface. Store the core at in situ temperature in darkness for as short as possible before tracer injection, ideally less than $1 \mathrm{~h}$.

\section{Tracer injection and incubation}

Inject $2 \mu \mathrm{L}$ tracer solution containing $10 \mathrm{KBq}^{35} \mathrm{SO}_{4}{ }^{2-}$ dissolved in sterile seawater through each of the Sikaflex plugs. Incubate at in situ temperature for $2 \mathrm{~h}$.

\section{Termination}

Remove the water film on the surface with a syringe and dispose it as radioactive waste. Place the core upside-down on a piston for extrusion so that the deepest sediment with the lowest sulfate reduction rates is handled before the sediment from near the surface that now have high concentrations of ${ }^{35} \mathrm{~S}$-TRIS. Stop the incubation by extruding the core in $1 \mathrm{~cm}$ steps and mix each subsample with $6 \mathrm{~mL} \mathrm{20 \%} \mathrm{Zn-acetate} \mathrm{in} \mathrm{a}$ $50 \mathrm{~mL}$ centrifuge tube. Freeze the samples immediately at $-20^{\circ} \mathrm{C}$. The extrusion is best performed with the piston standing in a large shallow tray to contain the unavoidable contamination of the surroundings.

\section{Distillation}

Thaw the samples, add $30 \mathrm{~mL}$ water to facilitate quantitative pipetting of the supernatant and centrifuge at $500 \mathrm{G}$ for 5 min to roughly separate the sulfate that is soluble from the TRIS that is all insoluble after fixation with $\mathrm{Zn}^{2+}$. Transfer 0.5 $\mathrm{mL}$ supernatant together with $4.5 \mathrm{~mL} 20 \% \mathrm{Zn}$-acetate and 15 $\mathrm{mL}$ scintillation cocktail to a $20 \mathrm{~mL}$ scintillation vial for determination of ${ }^{35} \mathrm{~S}$ in sulfate. Decant and dispose the remaining fluid as radioactive waste. Transfer the sediment to the reaction flask by flushing with a small amount of water. Add 20
mL DMSO, one drop of silicone-based anti-foam (Dow 362134D), and a strong almond-shaped magnetic stirring bar. Close the reaction flasks and connect the aerosol trap (0.1 M Citrate buffer at $\mathrm{pH} 4$ ) and the $\mathrm{H}_{2} \mathrm{~S}$ trap (5 mL 5\% Zn-acetate plus one drop of anti-foam). Start the $\mathrm{N}_{2}$ flow (ca. $10 \mathrm{~mL}$ $\mathrm{min}^{-1}$ ) and flush for $10 \mathrm{~min}$ to expel most $\mathrm{O}_{2}$ from the reac-

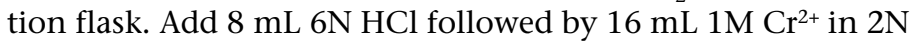
$\mathrm{HCl}$ with syringes through the valve and distill for $2 \mathrm{~h}$. During the distillation the TRIS will be converted to $\mathrm{H}_{2} \mathrm{~S}$ and carried to the $\mathrm{H}_{2} \mathrm{~S}$ trap where it is precipitated as white $\mathrm{ZnS}$. Sulfate will remain in the reaction flask and can be disposed as obnoxious smelling (DMS) radioactive waste. Transfer the full content of the $\mathrm{H}_{2} \mathrm{~S}$ trap to a $20 \mathrm{~mL}$ scintillation vial together with $15 \mathrm{~mL}$ scintillation fluid. Place the scintillation vials containing the supernatant sample and the TRIS sample back to back in the scintillation counter and quantify the activity of ${ }^{35} \mathrm{~S}$ in each sample.

\section{Calculations}

Calculate the total amount of water in each sample from the sediment volume, the sediment porosity, the added $\mathrm{Zn}$ acetate, and the water added before centrifugation. Calculate the total amount of ${ }^{35} \mathrm{SO}_{4}{ }^{2-}$ at the end of the incubation $\left(A_{\mathrm{SO}_{4}{ }^{2-}}\right)$ from the supernatant subsample and the total amount of water. Calculate the fraction of sulfate that has been reduced (F) from $\mathrm{A}_{\mathrm{TRIS}}$ and $\mathrm{A}_{\mathrm{SO}_{4}{ }^{2-}}$. Calculate the sulfate reduction rate for each sample according to Eq. 1.

\section{Appendix}

\section{Reagents}

Scintillation cocktail with high capacity for ionic strength and water (e.g., National Diagnostics Ecoscint XR)

0.1 M Citrate buffer for aerosol trap:

- 19.2 g citric acid

- $1000 \mathrm{~mL} \mathrm{H}_{2} \mathrm{O}$

- $4 \mathrm{~g} \mathrm{NaOH}$

- Adjust to $\mathrm{pH} 4$

$5 \% \mathrm{ZnAc}$ for $\mathrm{H}_{2} \mathrm{~S}$ trap:

- 50 g Zinc acetate

- $950 \mathrm{~mL} \mathrm{H}_{2} \mathrm{O}$

$6 \mathrm{~N} \mathrm{HCl}$ for liberation of acid-volatile sulfur during distillation

$1 \mathrm{M} \mathrm{CrCl}_{3}$ in $2 \mathrm{~N} \mathrm{HCl}$ :

- $1000 \mathrm{~g} \mathrm{CrCl}_{3}$

- $640 \mathrm{~mL} \mathrm{HCl}, 37 \%$

- $3440 \mathrm{~mL} \mathrm{H}_{2} \mathrm{O}$

Reduction of $1 \mathrm{M} \mathrm{CrCl}_{3}$ from $\mathrm{Cr}^{3+}$ to $\mathrm{Cr}^{2+}$. Used for reduction of $\mathrm{S}_{0}$ and $\mathrm{FeS}_{2}$ to $\mathrm{H}_{2} \mathrm{~S}$ during distillation:

- Place $1 \mathrm{~kg}$ zinc pellets in a $2 \mathrm{~L}$ reaction flask and cover with $2 \mathrm{~N} \mathrm{HCl}$.

- Purge the pellets with $\mathrm{N}_{2}$ for at least $10 \mathrm{~min}$. 
- Discharge and dispose the acid while maintaining $\mathrm{N}_{2}$ atmosphere.

- Pour the $\mathrm{CrCl}_{2}$ solution over the zinc pellets and continue $\mathrm{N}_{2}$ purging.

- Await color change from dark green $\left(\mathrm{Cr}^{3+}\right)$ to clear blue $\left(\mathrm{Cr}^{2+}\right)$.

- Transfer aliquots to $60 \mathrm{~mL}$ disposable syringes through a filter.

- Seal the tip and store the syringes at $5^{\circ} \mathrm{C}$ (keeps for a few days).

- Cover the zinc pellets with $2 \mathrm{~N} \mathrm{HCL}$ and purge for a few minutes. Discharge and dispose the acid and store the clean $\mathrm{Zn}$ pellets in the reaction flask until next use.

\section{References}

Bak, F., G. Scheff, and K. H. Jansen. 1991. A rapid and sensitive ion chromatographic technique for the determination of sulfate and SRRs in fresh-water lake-sediments. Fems Microbiol. Ecol. 85:23-30 [doi:10.1111/j.1574-6968.1991. tb04694.x].

Bortkiewicz, L. J. 1898. Das Gesetz der kleinen Zahlen.

Canfield, D. E. 1993. Organic matter oxidation in marine sediments, p. 333-363. In R. Wollast, L. Chou, and F. Mackenzie [eds.], Interactions of carbon, nitrogen, phosphorus and sulfur. Biogeochemical Cycles and Global Change. NATO ASI Series. Springer.

—, E. Kristensen, and B Thamdrup. 2005. Aquatic geomicrobiology. Elsevier.

—, J. Farquhar, and A. L. Zerkle. 2010. High isotope fractionations during sulfate reduction in a low-sulfate euxinic ocean analog. Geology 38:415-418 [doi:10.1130/G30723.1].

Cline, J. D. 1969. Spectrophotometric determination of hydrogen sulfide in natural waters. Limnol. Oceanogr. 14:454458 [doi:10.4319/lo.1969.14.3.0454].

de Beer, D., and others. 2005. Transport and mineralization rates in North Sea sandy intertidal sediments, Sylt-Rømø Basin, Wadden Sea. Limnol. Oceanogr. 50:113-127 [doi:10. 4319/1o.2005.50.1.0113].

de Brabandere, L., B. Thamdrup, N. P. Revsbech, and R. Foadi. 2012. A critical assessment of the occurence and extent of oxygen contamination during anaerobic incubations utilzing commercially available vials. J. Microbiol. Methods 88:147-154 [doi:10.1016/j.mimet.2011.11.001].

Elsgaard, L. 2000. Rubber stoppers used with sulphidic media: a note of caution. World J. Microb. Biot. 16:571-572 [doi:10.1023/A:1008909530445].

Fossing, H., and B. B. Jørgensen. 1989. Measurement of bacterial sulfate reduction in sediments - evaluation of a singlestep chromium reduction method. Biogeochemistry 8:205222 [doi:10.1007/BF00002889].

— radiolabeled sulfur-compounds in anoxic seawater. Biogeochemistry 9:223-245 [doi:10.1007/BF00000600].

—, S. Thode Andersen, and B. B. Jørgensen. 1992. Sulfur isotope exchange between S-35 labeled inorganic sulfurcompounds in anoxic marine-sediments. Mar. Chem. 38:117-132 [doi:10.1016/0304-4203(92)90071-H].

—, T. G. Ferdelman, and P. Berg. 2000. Sulfate reduction and methane oxidation in continental margin sediments influenced by irrigation (South-East Atlantic off Namibia). Geochim. Cosmochim. Acta 64:897-910 [doi:10.1016/ S0016-7037(99)00349-X].

Goldhaber, M. B., and I. R. Kaplan. 1975. Controls and consequences of sulfate reduction rates in recent marine sediments. Soil Sci. 119:42-55 [doi:10.1097/00010694197501000-00008].

Gröger, J., J. Franke, K. Hamer, and H. D. Schulz. 2009. Quantitative recovery of elemental sulfur and improved selectivity in a chromium-reducible sulfur distillation. Geostand. Geoanal. Res. 33:17-27 [doi:10.1111/j.1751-908X.2009. 00922.x].

Hansen, J. W., B. Thamdrup, and B. B. Jørgensen. 2000. Anoxic incubation of sediment in gas-tight plastic bags: A method for biogeochemical process studies. Mar. Ecol. Prog. Ser. 208:273-282 [doi:10.3354/meps208273].

Holmer, M., and P. Storkholm. 2001. Sulphate reduction and sulphur cycling in lake sediments: a review. Freshw. Biol. 46:431-451 [doi:10.1046/j.1365-2427.2001.00687.x].

Howarth, R. W., and A. Giblin. 1983. Sulfate reduction in the salt marshes at Sapelo Island, Georgia. Limnol. Oceanogr. 28:70-82 [doi:10.4319/lo.1983.28.1.0070].

— surement of sulfate reduction in salt marsh sediments. Limnol. Oceanogr. 29:598-608 [doi:10.4319/lo.1984.29.3. 0598].

Hsieh, Y. P., and C. H. Yang. 1989. Diffusion methods for the determination of reduced inorganic sulfur species in sediments. Limnol. Oceanogr. 34:1126-1129 [doi:10.4319/lo. 1989.34.6.1126].

Jansen, S., E. Walpersdorf, U. Werner, M. Billerbeck, M. E. Bottcher, and D. De Beer. 2009. Functioning of intertidal flats inferred from temporal and spatial dynamics of $\mathrm{O}_{2}$, $\mathrm{H}_{2} \mathrm{~S}$, and $\mathrm{pH}$ in their surface sediment. Ocean Dynam. 59:317-332 [doi:10.1007/s10236-009-0179-4].

Ivanov, M. V. 1956. Isotopes in the determination of the sulfate-reduction rate in Lake Belovod. Microbiologiya 25:305309.

. 1968. Microbiological processes in the formation of sulfur deposits. Israel Program for Scientific Translations.

Jørgensen, B. B. 1977. Sulfur cycle of a coastal marine sediment (Limfjorden, Denmark). Limnol. Oceanogr. 22:814832 [doi:10.4319/lo.1977.22.5.0814].

- 1978. Comparison of methods for the quantification of bacterial sulfate reduction in coastal marine-sediments.1. Measurement with radiotracer techniques. Geomicrobiol. J. 1:11-27 [doi:10.1080/01490457809377721].

- 1982. Mineralization of organic-matter in the sea bed-the role of sulfate reduction. Nature 296:643-645 
[doi:10.1038/296643a0].

, and T. Fenchel. 1974. Sulfur cycle of a marine sediment model system. Mar. Biol. 24:189-201 [doi:10.1007/ BF00391893].

- and S. Kasten. 2006. Sulfur cycling and methane oxidation, pp. 271-309. In H. D. Schulz and M. Zabel (eds.), Marine geochemistry, 2nd ed. Springer [doi:10.1007/3-54032144-6_8].

Kallmeyer, J., T. G. Ferdelman, A. Weber, H. Fossing, and B. B. Jørgensen. 2004. A cold chromium distillation procedure for radiolabeled sulfide applied to sulfate reduction measurements. Limnol. Oceanogr. Methods 2:171-180 [doi:10. 4319/lom.2004.2.171].

King, G. M. 2001. Radiotracer assays (S-35) of sulfate reduction rates in marine and freshwater sediments, p. 489-500. In Methods in microbiology, Vol 30. Academic Press Ltd.

Meier, J., A. Voigt, and H. D. Babenzien. 2000. A comparison of S-35-SO42- radiotracer techniques to determine sulphate reduction rates in laminated sediments. J. Microbiol. Methods 41:9-18 [doi:10.1016/S0167-7012(00)00144-5].

Middelburg, J. J. 1989. A simple rate model for organic-matter decomposition in marine-sediments. Geochim. Cosmochim. Acta 53:1577-1581 [doi:10.1016/00167037(89)90239-1].

Moeslund, L., B. Thamdrup, and B. B. Jørgensen. 1994. Sulfur and iron cycling in a coastal sediment - radiotracer studies and seasonal dynamics. Biogeochemistry 27:129-152.

Rosser, H. R., and W. A. Hamilton. 1983. Simple assay for accu- rate determination of [S-35] sulfate reduction activity. Appl. Environ. Microbiol. 45:1956-1959.

Singer, P. E., and W. Stumm. 1970. Acidic mine drainage: The ratedetermining step. Science 167:1121-1123 [doi:10.1126/ science.167.3921.1121].

Sorokin, Y. I. 1962. Experimental investigation of bacterial sulfate reduction in the Black Sea using S-35. Microbiology (Engl. transl.) 31:329-335.

Tarpgaard, I. H., H. Røy, and B. B. Jørgensen. 2011. Concurrent low- and high-affinity sulfate reduction kinetics in marine sediment. Geochim. Cosmochim. Acta 75:2997-3010 [doi:10.1016/j.gca.2011.03.028].

Teubner, B. G., and W. Bruchle. 2003. Confidence intervals for experiments with background and small numbers of events. Radiochim. Acta 91:71-80 [doi:10.1524/ract.91.2. 71.19989].

Ulrich, G. A., L. R. Krumholz, and J. M. Suflita. 1997. A rapid and simple method for estimating sulfate reduction activity and quantifying inorganic sulfides. Appl. Environ. Microbiol. 63:1627-1630.

Zhabina, N. N., and I. I. Volkov. 1978. A method of determination of various sulfur compounds in sea sediments and rocks, p. 735-746. In W. E. Krumbein [ed.], Environmental biogeochemistry and geomicrobiology. Ann Arbor Sci.

Submitted 13 July 2013 Revised 13 February 2014 Accepted 28 March 2014 